\title{
How to Increase the h-BN Crystallinity of Microfilms and Self-Standing Nanosheets: A Review of the Different Strategies Using the PDCs Route
}

\author{
Sheng Yuan ${ }^{1,2}$, Catherine Journet ${ }^{1}$, Sébastien Linas ${ }^{1}$, Vincent Garnier ${ }^{2}$, Philippe Steyer ${ }^{2}$, \\ Stéphane Benayoun ${ }^{3}$, Arnaud Brioude ${ }^{1}$ and Bérangère Toury ${ }^{1, *}$ \\ 1 Laboratoire des Multimatériaux et Interfaces, UMR CNRS 5615, Université de Lyon, LYON1, \\ F-69622 Villeurbanne, France; sheng.yuan@insa-lyon.fr (S.Y.); catherine.journet@univ-lyon1.fr (C.J.); \\ sebastien.linas@univ-lyon1.fr (S.L.); arnaud.brioude@univ-lyon1.fr (A.B.) \\ 2 Matériaux Ingénierie et Science, UMR CNRS 5510, INSA de Lyon, Université de Lyon, F-69621 Villeurbanne, \\ France; vincent.garnier@insa-lyon.fr (V.G.); philippe.steyer@insa-lyon.fr (P.S.) \\ 3 Laboratoire de Tribologie et Dynamique des Systèmes, Ecole Centrale de Lyon, F-69130 Ecully, France; \\ stephane.benayoun@ec-lyon.fr \\ * Correspondence: toury@univ-lyon1.fr; Tel.: +33-4-7243-3612
}

Academic Editors: Umit B. Demirci, Philippe Miele and Pascal G. Yot Received: 7 April 2016; Accepted: 3 May 2016; Published: 13 May 2016

\begin{abstract}
Hexagonal boron nitride (h-BN) is a well-known material whose use is almost restricted to lubricating applications in domains ranging from metallurgy to cosmetics. Howover, h-BN displays many other interesting properties, opening new perspectives for other engineering applications, such as as a solid lubricant in aeronautics, as the perfect substrate to graphene for electronic devices, etc. However, all these promising developments require tailored h-BN shapes displaying a high level of crystallization, ensuring its properties for the long term. Here, we developed three strategies, all associated with the Polymer Derived Ceramics (PDCs) route, to prepare highly crystallized supported thick coatings and self-standing nanosheets. The first strategy concerns the innovative implementation of a Rapid Thermal Annealing to prepare micrometric h-BN coatings on thermal sensitive substrates. Compared to conventional treatment the crystallization of h-BN has successfully lowered to about $300{ }^{\circ} \mathrm{C}$. The second strategy consists of an additivation of the used polymer precursor. Effect of lithium nitride as a crystallization promoter was investigated lowering the onset crystallization temperature from $1400{ }^{\circ} \mathrm{C}$ (traditionally) to $1000^{\circ} \mathrm{C}$. This novel synthetic route allows preparing self-standing highly crystallized h-BN nanolayers. Finally, the third strategy is based on a unique combination of the PDCs route with Spark Plasma Sintering to profit of both approaches. This original method leads to large and well-crystallized flakes available for a subsequent exfoliation.
\end{abstract}

Keywords: h-BN; PDCs; 2D nanolayers; coatings; nanosheets

\section{Introduction}

Hexagonal boron nitride ( $\mathrm{h}-\mathrm{BN})$ is a famous non oxide ceramic known and appreciated for its numerous interesting properties, such as a high thermal conductivity, an excellent thermal chock resistance, a high resistance against oxidation $\left(850^{\circ} \mathrm{C}\right.$ under air), a good chemical inertness [1,2], etc. Based on this non exhaustive list of important properties, it is easy to understand the key role of h-BN for real or potential applications. Actually, h-BN can be found many fields ranging from cosmetics to metallurgy passing by aeronautics or battery [1].

Another very interesting specificity of h-BN is linked to its structural similarity to graphite doing of themselves twin materials [3]. Actually, the h-BN progression is always directly linked to graphite counterparts. Examples are numerous, such as the preparation of boron nitride fibers in replacement of 
the carbon ones to be used at high temperature under air [4-8] the synthesis of boron nitride nanotubes after the discovery of the CNTs in the early 1990s [9-11], the preparation of analogue boron nitride fullerene/nanocage somewhat latter $[12,13]$ and more recently the myriad of studies to get boron nitride monolayers within the explosion of graphene $[3,14,15]$. All these examples show that the shape given to the ceramic is at least as important as the material itself, meaning that the shaping is essential to ensure potential applications.

The production of commercial h-BN powders is now completely mastered from an oxygen-containing boron compound reacting with a nitrogen-containing source [1,16-18]. The use of such powders is clearly convenient to provide sintered pieces but really restrains the possibility to reach others specific shapes (fibers, foams, coatings, etc.) In the latter case, a versatile alternative has to be found. The Polymer Derived ceramics (PDCs), developed in the late 1960s by Chantrell and Popper [19] for a non-oxide system is undoubtedly a good choice [20]. This route consists in the synthesis of very pure preceramic polymer from tailored molecular precursor. The preceramic polymer (liquid, soluble or fusible) can be then easily shaped into the convenient shape by means of dip- spin-coating, casting, melt-spinning [21], etc. Followed by an appropriate thermal treatment. The preceramic polymer body is then converted into hexagonal boron nitride while maintaining the desired shape. Obviously, the selection of the starting precursor is essential and should follow guidelines. Among all available precursors [22-24], borazine $\left(\mathrm{B}_{3} \mathrm{~N}_{3} \mathrm{H}_{6}\right)$ or polyborazilene (PBN) $\left(-\left(\mathrm{B}_{3} \mathrm{~N}_{3} \mathrm{H}_{4}\right)_{\mathrm{n}}-\right)$ [25-29], the latter being directly derived from the polycondensation of the former, are very attractive because they are prepared through a reproducible synthesis, whitout any contaminant within compounds and a perfect $\mathrm{B} / \mathrm{N}$ stoichiometry... PBN, which presents the advantage of a lower volatility and a better ceramic yield, is always preferred to borazine [30].

For half a decade, our group focused attention on thick h-BN coating deposited on metallic substrate especially on titanium to get self-lubricating devices available in aeronautics industry [31-33]. Actually, thanks to its lamellar structure combined to its important oxidation resistance even at high temperature under air, h-BN is one of the best candidates for protecting metal components in engineering. However, to give a high protectiveness, the ceramic may reach a high level of crystallization, which becomes a key parameter to manage. Traditionally, thin h-BN coatings are prepared through conventional sputtering [34], PLD [35,36], CVD and derivatives [37-42], these latter being the most studied [43]. Moreover, on top of the heavy equipment needed [44], coatings often display a low crystallinity, oxygen contamination or a non stoichiometric $\mathrm{B} / \mathrm{N}$ ratio [43]. In this context, the PDCs route appears as a relevant alternative to get advanced coatings. The use of a liquid phase allows a simple shaping by means of dip- or spin-coating able to control the thickness [45]. A review from 2011 [46] reports studies on the synthesis of h-BN coatings by preceramic polymers. Among them, we can cite the dibromoborane-dimethyl sulfide [47], the tris(alkylamino)borane [48,49], the alkylaminoborazine and derivatives [30,50], the borazine [30] and the PBN [30-33,45,50-53]. Hence, there are many precursor sources, but, the best results, in terms of homogeneity and purity, are systematically obtained with PBN. Actually, by controlling the polycondensation step, PBN can be prepared as a liquid polymer easy to handle and to shape. Besides, an appropriate thermal treatment allows easily converting the green preceramic coating into a contaminant-free crystallized h-BN one, the ceramic crystallization remaining a key parameter to get efficient coated devices.

More recently, motivated by the veritable craze for graphene (G), the current 2D superstar material, we have been witnessing to an increasing demand in BN nanolayers to be used as graphene substrate to keep advantages of its remarkable transport properties [54]. Actually, the common use of silica as insulating substrate to get a handled device remains insufficient to prepare efficient systems, its surface imperfections significantly affects the supported graphene carrier mobility. In that context, many studies claim the potential of h-BN as suitable dielectric substrate for graphene [55-57]. Actually, the perfect lattice matching of h-BN with graphene [58] coupled with the fact that h-BN has an atomically flat and dangling bond-free surface, will ensure no charge traps at the G/h-BN interface and consequently will increase of graphene's carrier mobility $[59,60]$. These constraints explained 
efforts to target uniform thickness, large domain size and high crystallinity. From these guidelines, two options can be distinguished, either a growth of h-BN by CVD or an exfoliation of large single crystals. Today, many studies are devoted to the first way, exploring a variety of transition metals as substrate, such as $\mathrm{Ni}$ and Fe films, $\mathrm{Pt}$ foil, $\mathrm{Cu}-\mathrm{Ni}$ alloys, [61-72], the most common remaining $\mathrm{Cu}$ foils [73-75]. Even if results are more and more relevant, with the increasing size of domains, this route needs heavy equipment and reproducibility is strongly dependent on the used apparatus, which really limits its development. Besides, the production is limited. Keeping these issues in mind, the second way, involving exfoliation of single crystals, is relevant if an accessible source of pure and highly crystallized crystals becomes available [76]. It is well-known that the group of Watanabe at the National Institute for Materials Science (NIMS) [77,78] can prepare this kind of high quality single crystals using the High Pressure High Temperature (HPHT) process, but the whole procedure runs through severe production conditions and long treatment time [76] making its widespread restricted. Commercial sources $[17,18]$ are more reachable but the quality remains characterized by a high level of defects and relatively small crystalline areas [76]. In that latter case, synthetic material can suffer of a lack of crystallization, often linked to the synthetic process used.

In this review, we focused our attention on three main strategies developed in the group in order to increase the h-BN crystallization for supported thick coatings and self-standing nanosheets prepared through the PDCs route. Our approach is based either on the process, or on the chemistry of reactants (sometimes on both). If the easiest way to enhance crystallization consists in a simple increase of the final treatment temperature, this is not systematically allowed, for apparatus limitations reason, due to a cost restrictions or due to substrate specificities (thermal sensitivity for example). Alternatives have, then, to be found. Our first studies are focused on the ceramization process. Hence, we explored the possibility of preparing h-BN coatings on metallic substrates using an innovative IR irradiation annealing process. Since the metallic substrate reflects IR radiation, only the outer preceramic coating is irradiated, preserving the subjacent substrate integrity. The second strategy is directly linked to the chemistry, with the additivation of the polymeric precursor with a crystallization promoter, acting as a catalyst to favor the crystallization occurring during the ceramization step. Finally, to go further, we implemented a third strategy combining the additivation and the use of a particular sintering process, which is the Spark Plasma Sintering (SPS).

\section{First strategy: Rapid Thermal Annealing (RTA)}

As mentioned above, performances of h-BN protective coating are closely correlated to its crystallization state which traditionally requires an appropriate thermal treatment of the green material to favor its ceramization and crystallization at a temperature ranging from 1600 to $1800{ }^{\circ} \mathrm{C}$ under an inert atmosphere. Considering these drastic conditions, only ceramic substrates can be used, metals thermally sensitive or susceptible to phase transitions. However, for specific applications, metallic substrates can be required (e.g., titanium based alloys for the aeronautic industry), that is why we propose an alternative annealing method using infrared (IR) irradiation with either a simple halogen lamp or an advanced Rapid Thermal Annealing (RTA) (Figure 1) furnace instead of a conventional resistive one. In this configuration, the IR radiation is absorbed by the green material to initiate the polymer-to-ceramic conversion, while the metallic substrate reflects the highest part of the irradiation, meaning that only the pre-ceramic coating is heated during the annealing preserving the sustrate.

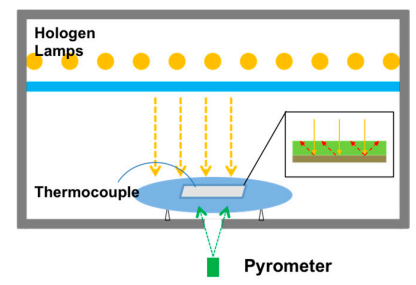

Figure 1. Rapid Thermal Annealing system. 


\subsection{Influence of the Annealing Temperature}

In order to study the influence of the annealing temperature $v$ s the h-BN crystallization, in the first phase, we prepare 5 samples, a titanium substrate $\left(2 \times 10 \times 50 \mathrm{~mm}^{3}\right)$ dip-coated in liquid pure PBN then heat treated under a halogen lamp heated at $800,900,1000,1100$ and $1200{ }^{\circ} \mathrm{C}$ for $1 \mathrm{~h}$ in a gloves box, leading to samples TiBN800 to TiBN1200, respectively. The so-obtained coatings are homogenous and recovering according to the microscopic observations. A representative example of the surface is shown in Figure 2.

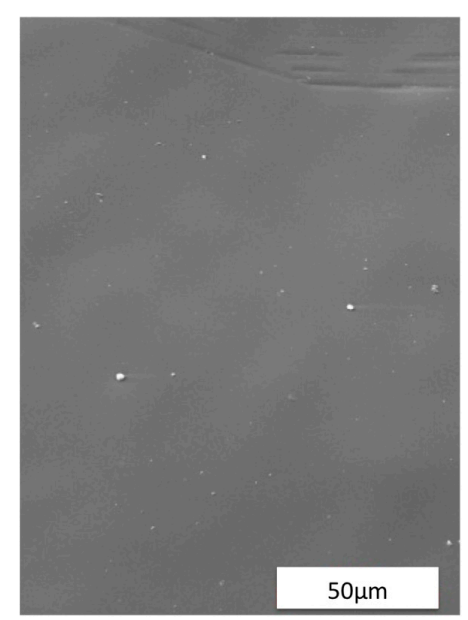

Figure 2. SEM image of sample TiBN1200, representative of the homogeneity of the top surface.

AFM measurement performed on TiBN1200 shows a flat surface within large area and gives a root-mean-square roughness (RMS) of $20 \mathrm{~nm}$ [33]. The thickness of the coating can be adjusted by the dip-coating parameters and layer number. For instance, after optimization, we obtained a defect-free $16 \mu \mathrm{m}$-thick coating. Such a result is of prime interest, since the ensuing coating is thicker than most of BN coatings obtained either by PDCs [79-81], CVD [62] or PVD [82]. Figure 3 shows IR spectra of pure PBN (red curve) compared to TiBN1200 (black curve). Both spectra show the loss of the two signals assigned to B-H and N-H vibrations, respectively at 2510 et $3450 \mathrm{~cm}^{-1}$, evidencing the ceramization of PBN during annealing. Furthermore, the presence of both expected signals for h-BN at 1378 and at $790 \mathrm{~cm}^{-1}$ respectively characteristic of B-N stretching and B-N-B bending vibration modes, ensure the preparation of the expected ceramic.

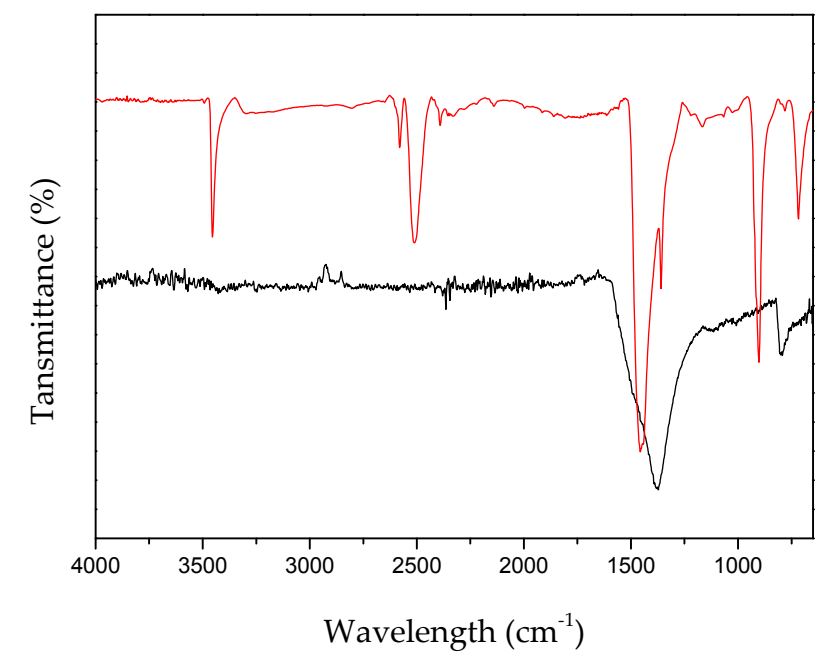

Figure 3. FTIR spectra recorded on pure PBN (red) and TiBN1200 (black). 
The conversion of PBN into h-BN from 800 to $1200{ }^{\circ} \mathrm{C}$ was also evidenced by Raman analysis. Actually, Figure 4 shows that the broad $\mathrm{E}_{2 \mathrm{~g}}$ signal characteristic of amorphous preceramic becomes thinner and thinner revealing the upcoming hexagonal structure.

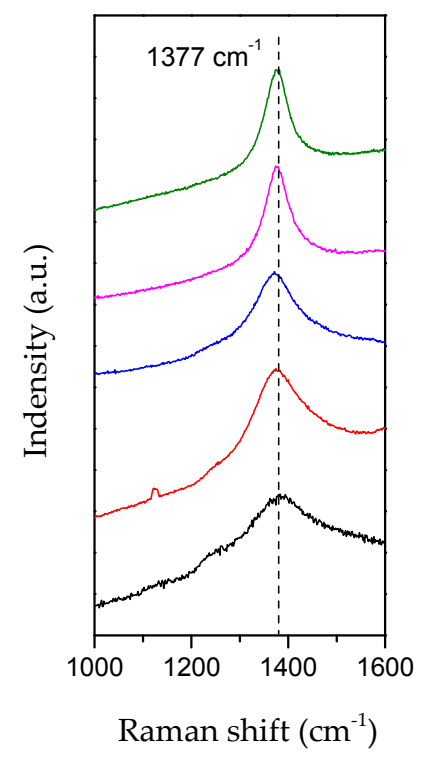

Figure 4. Raman spectra recorded on samples TiBN800 (black) to TiBN1200 (green).

The same analyses are also carried out by XRD on all the samples, driving to the same conclusion. In general, $\mathrm{h}-\mathrm{BN}$ crystallite displays pellet-like structure with the sheet extension parameters, $\mathrm{L}_{\mathrm{a}}$, much higher than the parallel layer's average stack height, $\mathrm{L}_{\mathrm{c}}$. In our case, both values can be estimated by the means of Raman and XRD, respectively. Calculation of $\mathrm{L}_{c}$ value is based on the well-known Sherrer's equation considering the (002) peak. Figure 5 displays the change in $\mathrm{L}_{\mathrm{c}}$ as a function of the applied annealing temperature. It appears that $\mathrm{L}_{\mathrm{c}}$ values increase from 1.42 to $1.71 \mathrm{~nm}$ as the thermal treatment temperature increases from 800 to $1200^{\circ} \mathrm{C}$. Moreover, Nemanich et al. reported a correlation between width and shift peak of $\mathrm{E}_{2 \mathrm{~g}}$ and the average crystallites size $\mathrm{L}_{\mathrm{a}}$ of $\mathrm{h}-\mathrm{BN}$ [83]. The crystallites size, $\mathrm{L}_{\mathrm{a}}$, calculated using the latter relation indicates (Figure 5) the same tendency as the $\mathrm{L}_{\mathrm{a}}$ increases from $1 \mathrm{~nm}$ to around $4.7 \mathrm{~nm}$, with increasing temperature.

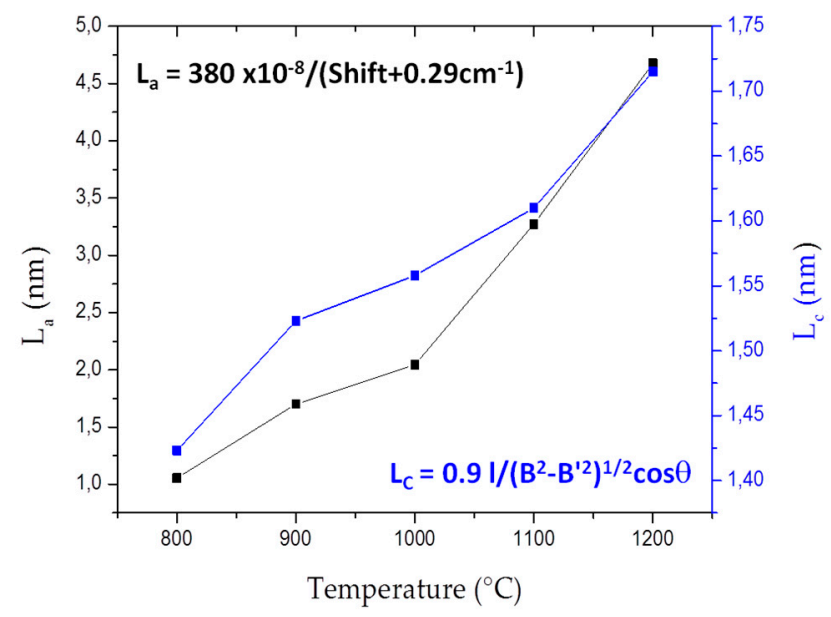

Figure 5. Graphs showing the evolution of $L_{c}$ (calculated from Sherrer's equation) (blue) and $\mathrm{L}_{\mathrm{a}}$ (calculated from Nemanich' correlation) (black) as function of the annealing temperature. 
This relatively small crystallite size is proved by direct HR-TEM observations showing the hexagonal structure and crystallite sizes around $5 \mathrm{~nm}$ [33]. Besides, we have shown that the ceramic is stable towards air. Actually, XPS chemical analyses, performed on two samples (one just after its synthesis, the other one after more than 2 months under air), reveals no further oxidation. The chemical composition $(\mathrm{B} / \mathrm{N})$ remains close to the stoichiometry [33].

In conclusion, it is interesting to notice that annealing at $1200^{\circ} \mathrm{C}$ using IR irradiation may give rise to crystallites characterized by almost the same crystallite size as that obtained via heat treatment in a resistive furnace at $1500{ }^{\circ} \mathrm{C}$, leading to a gain of $300{ }^{\circ} \mathrm{C}$ [8]. In addition, it has been proven that this alternative annealing allows decreasing the onset of crystallization temperature down to $900{ }^{\circ} \mathrm{C}$ using PBN as precursor.

\subsection{Influence of Annealing Process and Atmosphere (RTA)}

To reach a high annealing temperature while avoiding any overheating of he substrate, we used an advanced RTA furnace instead of the simple halogen lamp. The heating program is adapted to that quick process, i.e., a rapid temperature increasing $\left(8^{\circ} \mathrm{C} / \mathrm{s}\right)$ up to the plateau temperature $\left(\mathrm{Tp}=900^{\circ} \mathrm{C}\right)$ and the deliverance of 6 or 9 flashes of $5 \mathrm{~s}$ at $1350^{\circ} \mathrm{C}$ under $\mathrm{N}_{2}$ or Ar. Each flash is performed after the temperature reaches again the Tp. First, one can mention that the annealing atmosphere has no visible influence on the crystallization state of the final coating, since TiBN1350- $\mathrm{N}_{2}$ and TiBN1350-Ar present almost the same XRD and Raman signature of the surface. Second, the benefit of the higher temperature $\left(1350{ }^{\circ} \mathrm{C}\right)$ compared to the previous one $\left(1200{ }^{\circ} \mathrm{C}\right)$ is evidenced by the XRD analysis. Actually, according to the XRD data (Table 1), the interlayer parameter $d$ was calculated thanks to the Bragg's law is given to be $3.47 \AA$ vs. $3.60 \AA$ for TiBN1350-9f and TiBN1200, respectively, which is much closer to the theoretical value given to $3.33 \AA$ [33] In addition, Table 1 also shows that an increase in the number of flashes allows to get a ceramic with a $L_{c}$ reaching $3 \mathrm{~nm}$.

Table 1. Main XRD parameters obtained for samples TiBN1200, TiBN1350-9f and TiBN1350-6f.

\begin{tabular}{ccccc}
\hline Sample & $\theta_{\mathbf{0 0 2}}\left({ }^{\circ}\right)$ & $\mathbf{d}_{\mathbf{0 0 2}}\left({ }^{(}\right)^{\mathbf{1}}$ & FWHM(002) & Lc (nm) \\
\hline TiBN1200 & 24.5 & 3.60 & 4.83 & 1.7 \\
TiBN1350-9f & 25.8 & 3.44 & 2.9 & 3.0 \\
TiBN1350-6f & 25.3 & 3.52 & 2.8 & 2.9 \\
\hline \multicolumn{5}{r}{ 1 interlayer parameter calculated thanks to the Bragg'law. }
\end{tabular}

${ }^{1}$ interlayer parameter calculated thanks to the Bragg'law.

In summary, the whole study tends to show the real potential of an IR annealing to perform crystallized boron nitride, displaying a good chemical stability, at quite low temperature with an onset of crystallization as low as $900{ }^{\circ} \mathrm{C}$. However, the crystallization should even be improved and other advanced strategies should be studied and applied.

\section{Second Strategy: $\mathrm{Li}_{3} \mathrm{~N}$ as Crystallization Promoter}

Besides the process that can be adjusted to enhance the ceramic crystallization conditions, another tactic may consist in playing with the chemistry of reactants involved during the synthesis. Actually, there are intrinsic relationships existing between properties of both precursors (or solution) and the resulting final material. Hence, either modifying the chemical nature of the used precursor or additivating it with a crystallization promoter would play a key role on the final crystallinity of the ceramic. In that way, as already mentioned in the introduction, the used of PBN as preceramic precursor is particularly relevant $[30,50,51,84]$ since it is prepared through pure borazine that initially displays the expected targeted hexagonal arrangement [85]. Moreover, since the polymer is obtained without any solvent addition, only hydrogen is expected to be lost $[25,86-88]$ and no contaminant is present, whose presence may slow down the crystallization process. Some studies report the addition of calcium carbonate $[1,16,77,89]$ or lithium nitride to increase the final h-BN crystallization. 
However, $\mathrm{Li}_{3} \mathrm{~N}$ is more classically used for conversion of h-BN to c-BN at relatively low temperature and pressure [90-94]. Based on these relevant results, we decided to add lithium nitride ( $\mathrm{Li}_{3} \mathrm{~N}$ ) in pure PBN in order to lower the onset crystallization temperature [95].

\subsection{Evidence of $\mathrm{Li}_{3} \mathrm{~N}$ Effect}

First to highlight the key role of this additive in crystallization enhancement of the final ceramic, we performed Thermo Gravimetric Analyses (TGA) on two reference samples; pure PBN and PBN mixed with $\mathrm{Li}_{3} \mathrm{~N}$ micro powders (5wt. \%), respectively named PBN and PBN-Li $3 \mathrm{~N}$ (Figure 6).

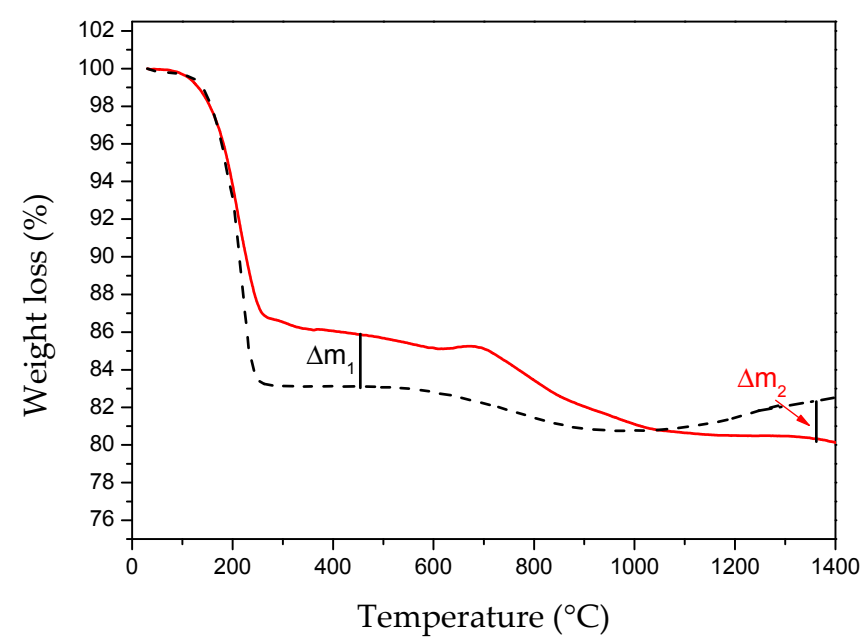

Figure 6. TGA curves recorded on two reference samples; pure polyborazilene (PBN) (dashed line) and $\mathrm{PBN}$ mixed with $\mathrm{Li}_{3} \mathrm{~N}$ micro powders (5wt. \%) (PBN-Li $\left.3 \mathrm{~N}\right)$ (red line).

Comparison of both curves shows three main differences. First, a lower weight loss for PBN-Li $3 \mathrm{~N}$ sample at $600{ }^{\circ} \mathrm{C}: 13 \%$ vs. $17 \%$ for PBN sample is observed, the difference $\left(\Delta \mathrm{m}_{1}\right)$ indicating the additive preservation. The second difference corresponds to a higher weight loss for the additivated sample between 600 and $1000{ }^{\circ} \mathrm{C}$ interpreted as the removal of the additive or a product derived from the latter stage. Based on previous articles, we can assume that at this temperature range, a reaction occurs between $\mathrm{Li}_{3} \mathrm{~N}$ and the former $\mathrm{BN}$ to get $\mathrm{Li}_{3} \mathrm{BN}_{2}[96,97]$. This specie can exist through two different structures $\alpha-\mathrm{Li}_{3} \mathrm{BN}_{2}$ and $\beta-\mathrm{Li}_{3} \mathrm{BN}_{2}$ melting at $860^{\circ} \mathrm{C}$ and $920^{\circ} \mathrm{C}$, respectively, so likely to be eliminated under the $\mathrm{N}_{2}$ flow. Finally, the last divergence comes from the behavior of both products up to $1200^{\circ} \mathrm{C}$. Actually, the TGA curve recorded on the BN derived from the PBN-Li 3 N sample stays stable up to $1400{ }^{\circ} \mathrm{C}$, meaning that the sample is not changing. Besides, the TGA curve from the BN produced from the pure PBN gains mass $\left(\Delta \mathrm{m}_{2}\right)$ and this non-expected behavior can be attributed to oxidation (with residual air in the chamber) [53] meaning that the sample is not stable and sensitive to oxidation probably because of a worse crystallization [98].

Further structural characterization by means of Raman spectroscopy and X-ray diffraction are performed on both TGA residues. First, both Raman spectra (Figure 7) exhibit a characteristic signature of hexagonal boron nitride, with a broad signal around $1367 \mathrm{~cm}^{-1}$ typical of the $\mathrm{E}_{2 \mathrm{~g}}$ mode peak of h-BN [83]. The first difference comes from the FWHM measured to be $52 \mathrm{~cm}^{-1} v s .38 \mathrm{~cm}^{-1}$ and the $\mathrm{L}_{\mathrm{a}}$ calculated [83] to be $8.6 \mathrm{~nm}$ vs. $38 \mathrm{~nm}$ respectively for the pure and additivated samples, meaning a better crystallization of the latter sample. The second difference comes from an additional signal within the PBN-Li 3 N derivative sample spectrum at $810 \mathrm{~cm}^{-1}$ and assigned to boron oxide [99] confirming the compound oxidation as previously suggested by TGA. 


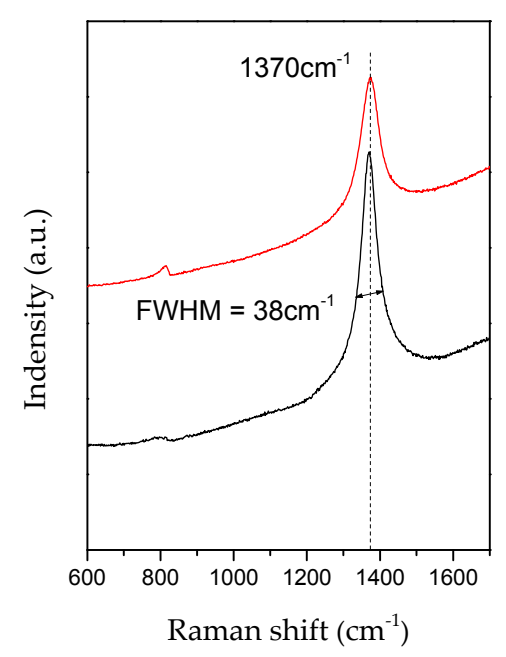

Figure 7. Raman spectra recorded on both TGA residues derived PBN (red) and PBN-Li 3 N (black).

XRD patterns, proposed on Figure 8, also present the signature of hexagonal boron nitride with a main signal at around $26.8^{\circ}$ corresponding to the (002) diffraction peak, according to the JCPDS file 009-0012. Moreover, examination of values reported on the Table 2 and corresponding to the main (observed or calculated) [33] XRD parameters clearly shows that the sample prepared with the pure $\mathrm{PBN}$ displays a lower crystallization compared to this obtained from $\mathrm{PBN}-\mathrm{Li}_{3} \mathrm{~N}$.

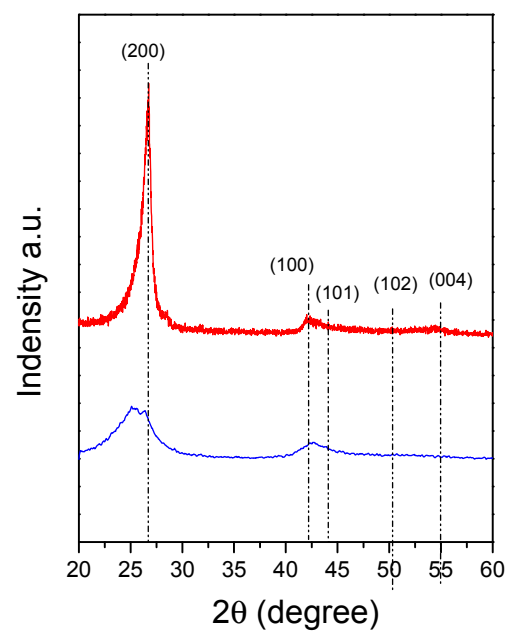

Figure 8. XRD patterns recorded on both TGA residues derived $\mathrm{PBN}$ (blue) and $\mathrm{PBN}-\mathrm{Li} \mathrm{i}_{3} \mathrm{~N}$ (red).

Table 2. Main XRD parameters of commercial h-BN and TGA residues derived PBN and PBN-Li 3 N.

\begin{tabular}{cccccccc}
\hline Sample & $\mathbf{d}_{\mathbf{0 0 2}}(\AA)$ & $\boldsymbol{\theta}_{\mathbf{0 0 2}}\left(^{\circ}\right)$ & FWHM $_{(\mathbf{0 0 2})}$ & $\boldsymbol{\theta}_{\mathbf{1 0}}\left(^{\circ}\right)$ & FWHM $_{(\mathbf{1 0 )}}$ & $\mathbf{L}_{\mathbf{c}}(\mathbf{n m})$ & $\mathbf{L}_{\mathbf{a}}(\mathbf{n m})$ \\
\hline Commercial h-BN & 3.31 & 26.9 & 0.35 & 41.7 & - & -1 & -1 \\
$\mathrm{Li}_{3} \mathrm{~N}-\mathrm{PBN}$ & 3.33 & 26.7 & 0.92 & 42.0 & 1.0 & 37.8 & 38.0 \\
PBN & 3.54 & 25.1 & 3.61 & 42.6 & 2.2 & 2.3 & 8.6 \\
\hline
\end{tabular}

${ }^{1}$ Since Scherrer's equation is limited for the range of crystallite sizes varying from 1 to $100 \mathrm{~nm}$, not calculable here.

The fact that this latter XRD pattern displays a shoulder towards the low $2 \theta$ values $\left(\sim 25^{\circ}\right)$, meaning a dispersion in the crystallites size, can be related to its very short stay at $1400^{\circ} \mathrm{C}$. By tailoring the ceramization parameters one can expect to enhance even more the crystallization state. 


\subsection{Influence of the Annealing Temperature on $h$-BN Crystallization}

In order to understand the chemical and structural mechanism occurring with the ceramic derived from the additivated precursor, a series of $\mathrm{BN}$ samples incorporating $\mathrm{Li}_{3} \mathrm{~N}(5 \mathrm{wt} . \%)$ and annealed at 600 , $800,1000,1200$ and $1400{ }^{\circ} \mathrm{C}$ (denoted, respectively LiBN01 to LiBN05) is prepared. Diffractogramms recorded on each sample are gathered in Figure 9. LiBN01 sample is completely amorphous, in good accordance with the TGA curve that shows that the catalytic effect is not expected at this lowest temperature. Regarding LiBN02, we evidenced a signature of turbostratic BN coupled with other signals attributed here to the $\mathrm{Li}_{3} \mathrm{BN}_{2}$. Our assomption is again confirmed with the formation, between 800 and $1000{ }^{\circ} \mathrm{C}$ of $\mathrm{Li}_{3} \mathrm{BN}_{2}$ from a reaction between $\mathrm{Li}_{3} \mathrm{~N}$ and the former $\mathrm{BN}$. From 1000 to $1400{ }^{\circ} \mathrm{C}$, differences within the XRD patterns remain marginal, with refining signals, meaning a decrease in the measured FWHM and calculated $\mathrm{d}_{002}$ values obtained on the (002) diffraction peak as attested in Figure 10. In conclusion, the beneficial effect of the addition of $\mathrm{Li}_{3} \mathrm{~N}$ within the $\mathrm{PBN}$ is clearly visible from $1000{ }^{\circ} \mathrm{C}$ and even more accentuated at 1200 and $1400{ }^{\circ} \mathrm{C}$.

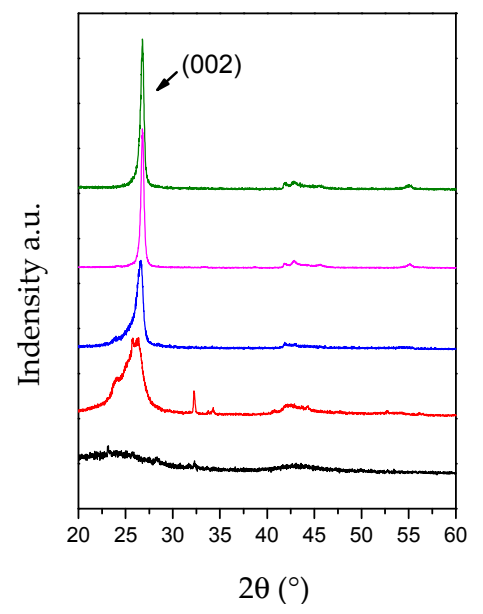

Figure 9. XRD patterns recorded on samples LiBN01 (black), LiBN02 (red), LiBN03 (blue), LiBN04 (magenta) and LiBN05 (green).

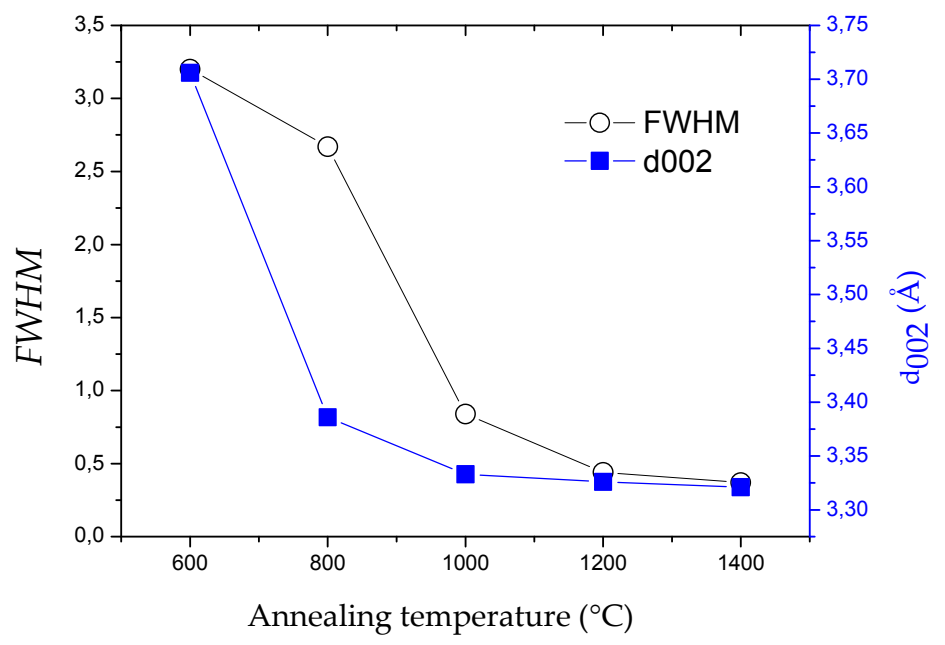

Figure 10. Influence of the annealing temperature on FWHM (black) and $\mathrm{d}_{002}$ (blue).

The proposed crystallization mechanism is based on previous studies reported by Bezrukov [100] and other groups $[97,101,102]$. At around $600-700{ }^{\circ} \mathrm{C}, \mathrm{Li}_{3} \mathrm{BN}_{2}$ formed by reaction between $\mathrm{Li}_{3} \mathrm{~N}$ and preceramic $\mathrm{BN}$, melts and infiltrates amorphous $\mathrm{BN}$ and dissolves it, leading to highly crystallized hexagonal boron nitride. 
The main interest in this additivation is to drastically decrease the crystallization temperature from traditionally, at least $1500{ }^{\circ} \mathrm{C}$ [25], to $1000-1200{ }^{\circ} \mathrm{C}$. To our knowledge, we are the first to demonstrate the additive activity of $\mathrm{Li}_{3} \mathrm{~N}$ when adding in a preceramic polymer and the heat treatment of that mixture.

\subsection{Thick $h$-BN Synthesis}

From this important result we decided to combine the use of an additivated polymer to a RTA thermal annealing to get crystallized h-BN coating over titanium substrate while preserving the latter integrity and saving time [31].

In that way, pure PBN is mixed with micro sized $\mathrm{Li}_{3} \mathrm{~N}$ powders, in 1,3 or $5 \mathrm{wt}$. $\%$ and stirred for $30 \mathrm{~min}$ in a gloves box. Still under argon, each solution is deposited on a titanium substrate, previously cleaned with ethanol. Coated samples are then kept at $200{ }^{\circ} \mathrm{C}$ for $1 \mathrm{~h}$ to avoid further important polymer volatilization. Finally, samples are placed in the RTA furnace and heated at $1200{ }^{\circ} \mathrm{C}$ under $\mathrm{N}_{2}$ underwent 9 flashes following a program described above. The 3 resulting samples are named TiBN1, TiBN3 and TiBN5. The naked substrate undergoing the same annealing is named TiBN0.

Observations made by SEM and proposed on a previous paper [31] show recovering and almost homogenous coatings presenting, moreover, more and more visible defects due to the original presence of the powder.

In order to study the ceramic crystallization, XRD was performed on the whole sample series. The corresponding patterns are proposed in Figure 11.

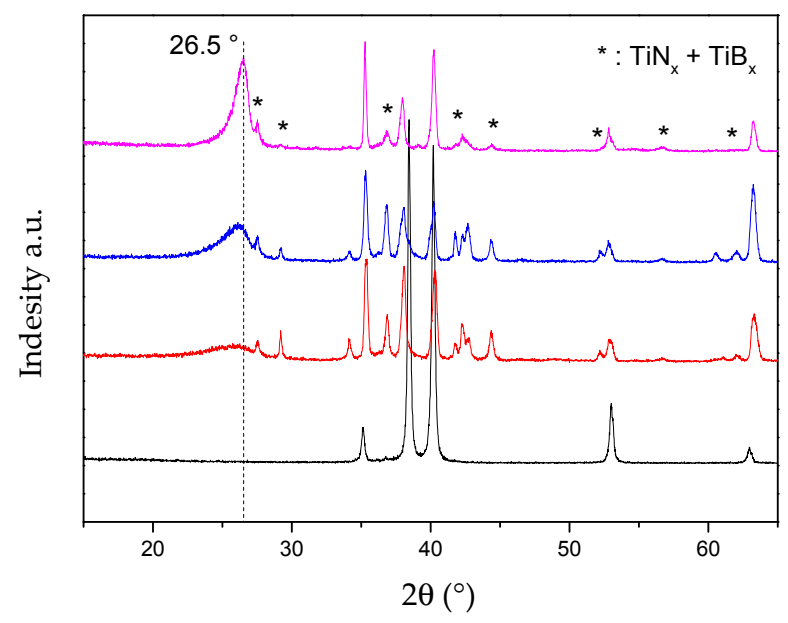

Figure 11. XRD patterns recorded on samples TiBN0 (black), TiBN1 (red), TiBN3 (blue) and TiBN5 (magenta).

Only regarding peaks corresponding to $\mathrm{h}-\mathrm{BN}$ at $26.7^{\circ}, 42.3^{\circ}$ and $44.4^{\circ}(2 \theta)$, they appear finer with the crystallization promoter ratio increasing. Besides, measured $\mathrm{FWHM}_{(002)}$ and calculated $\mathrm{d}_{002}$ and $\mathrm{L}_{002}$ values reported in Table 3 demonstrate that most the sample incorporates $\mathrm{Li}_{3} \mathrm{~N}$ in the pre-mixture, most it becomes crystallized. It has to be noticed that all the other signals display on the XRD patterns are attributed to either titanium or $\left(\mathrm{TiN}+\mathrm{TiB}_{2}\right)$ respectively, the substrate and the interface (according to the JCPDS files 087-0633 and 089-3923).

Table 3. Main XRD parameters of samples TiBN1, TiBN3 and TiBN5.

\begin{tabular}{ccccc}
\hline Sample & $\mathbf{d}_{\mathbf{0 0 2}}(\mathbf{A})$ & $\theta_{\mathbf{0 0 2}}\left(^{\circ}\right)$ & FWHM $_{(\mathbf{0 0 2})}$ & $\mathbf{L}_{\mathbf{c}}(\mathbf{n m})$ \\
\hline TiBN5 & 3.33 & 26.6 & 0.67 & 26 \\
TiBN3 & 3.41 & 26.1 & 0.92 & 19 \\
TiBN1 & 3.55 & 25.9 & 1.54 & 11 \\
\hline
\end{tabular}


In summary, we demonstrate here that it is possible to get crystallized h-BN coating on titanium at only $1200{ }^{\circ} \mathrm{C}$ for a total treatment duration of a few minutes. Increasing the IR irradiation time could still increase crystallization but in that case, the thermal conduction occurring from the coating to the substrate will modify the titanium structure (phase transition: $980^{\circ} \mathrm{C}$ ), which is not allowed. To the best of our knowledge this is the best compromise between the crystallization rate and the substrate preservation. Futher studies [31] have shown that coatings prepared with an additivated precursor and treated under RTA present very interesting mechanical and adhesion properties for tribological applications.

\subsection{BNNS Preparation}

If the availability of thick h-BN coatings on metallic substrate is very interesting for mechanical and tribological applications, recent works, essentially based on graphene heads towards 2D nanostructures preparation. In this new context, we decided to take advantage of the good results obtained on the PBN additivation to favor the synthesis of well-crystallized BNNSs [103].

Hence, we simply prepare a bulk sample using PBN additivated with $\mathrm{Li}_{3} \mathrm{~N}(5 \mathrm{wt}$. \%) annealed, under $\mathrm{N}_{2}$, at $1400{ }^{\circ} \mathrm{C}\left(1^{\circ} \mathrm{C} / \mathrm{min}\right)$ for $1 \mathrm{~h}$ after a 1-hour pre-stabilization at $200{ }^{\circ} \mathrm{C}$ (on a hot plate). Here again, high crystallization of the obtained white powder is clearly proved by Raman spectroscopy and XRD. Raman scattering spectrum, reported on Figure 12, is typical of h-BN with a unique signal at $1367 \mathrm{~cm}^{-1}$ displaying a weak FWHM value $\left(17 \mathrm{~cm}^{-1}\right)$.

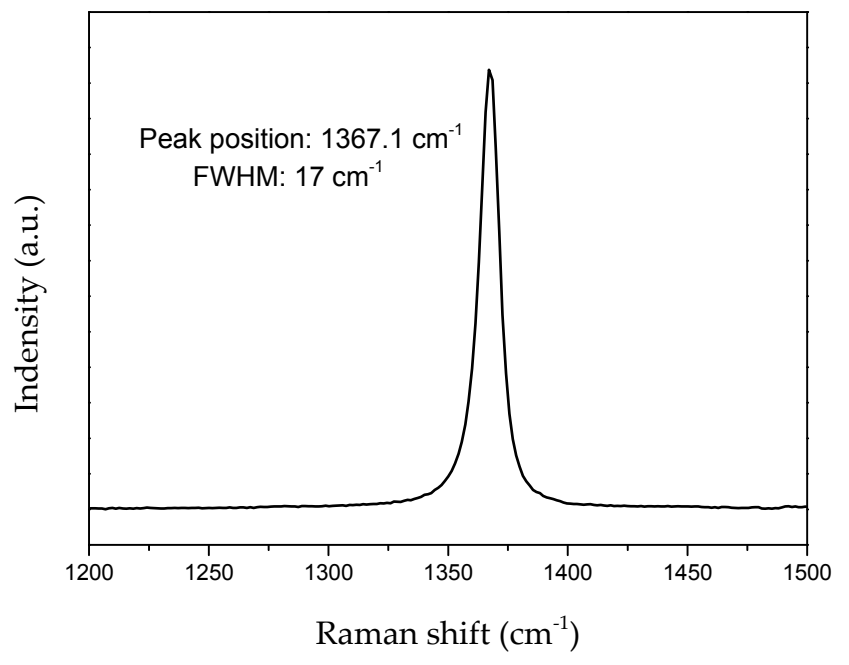

Figure 12. Raman spectrum recorded on bulk LiBN05.

Regarding, the XRD pattern (Figure 13) in comparison with commercial h-BN (HENZE BNP $\mathrm{GmbH}$ support) is also characteristic of highly crystallized h-BN with thin and well defined diffraction peaks at $2 \theta=26.9^{\circ}, 41.8^{\circ}, 44^{\circ}, 55.2^{\circ}, 75.9^{\circ}$ and $82.1^{\circ}$ corresponding to (002), (100), (101), (004), (110) and (112) crystallographic planes, respectively according to the JCPDS file 009-0012. However, we can note the absence of the (102) crystallographic plan expected at $50.3^{\circ}(2 \theta)$. In addition, taking into account the fact that calculated relative intensity of each peak (Table 4 ) are consistent with theoretical ones only for the (002) and (004) signals, suggest the synthesis of ceramic with 2D dimension. Two supplementary peaks can also be detected at $2 \theta=42.6^{\circ}$ and $45.6^{\circ}$ and attributed to rhombohedra BN (r-BN) (JCPDS file 045-1171). Structure of $r-B N$ is similar to that of $h-B N$ with a stacking of alternative atomic layers $\mathrm{ABC}-\mathrm{ABC}$ instead of $\mathrm{AB}-\mathrm{AB}$ for h-BN $[16,104]$. 


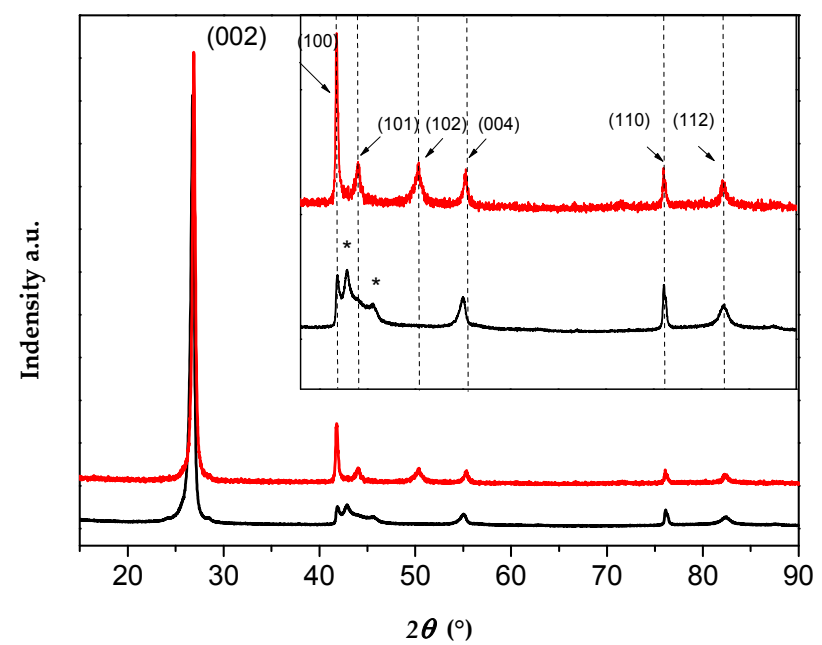

Figure 13. XRD patterns recorded on commercial h-BN (black) and on LiBN05 (red).

Table 4. Main XRD parameters of commercial h-BN and LiBN05.

\begin{tabular}{cccccccc}
\hline Signal Intensity & $\mathbf{( 2 0 0 )}$ & $\mathbf{( 1 0 0 )}$ & $\mathbf{( 1 0 1 )}$ & $\mathbf{( 1 0 2 )}$ & $\mathbf{( 0 0 4 )}$ & $\mathbf{( 1 1 0 )}$ & $\mathbf{( 1 1 2 )}$ \\
\hline Theoretical intensity & 100 & 15 & 6 & 15 & 6 & 5 & 5 \\
Calculated intensity & 100 & 3.7 & 2.5 & 0 & 5 & 2.8 & 2 \\
\hline
\end{tabular}

In order to confirm the sample microstructure, the raw powder is dispersed in ethanol under ultrasound, for a chemical exfoliation step, then observed by TEM. Figure 14 presents representative micrographs obtained on exfoliated BN. Figure $14 \mathrm{~b}$ displays diffraction contrats that are characteristics of the perfect sample crystallization. Misorientations between h-BN layers may explain those patterns as shown on the image at higher resolution (Figure 14a) where perfectly crystallized sheets are stacked on each other in a disorderly manner. This is also revealed by multiple spots in the corresponding Selected Area Electron Diffraction (SAED) patterns obtained on different sample areas (Figure 14a inset), and exhibiting severals sets of six hexagonal spots rotated with various angles, demonstrating the achievement of h-BN single crystals stacked respectively in a $\mathrm{AA}^{\prime}$ structure along the $c$-direction or in a more complex turbostratic structure. This relative rotation may be attributed to the stain induced by the rolled structure and the folding of sheets on themselves. The High Resolution Transmission Electron Microscopy (HRTEM) performed on a fine zone of one sheet shows the perfect atomic in-plane arrangement characteristic from the hexagonal lattice (Figure 14c). Several dark lines with interatomic distance measured at $3.33 \AA$ are experimentally measured on the edges of the sheet, giving its number of layers. The diffraction pattern associated with this sheet clearly exhibits hexagonal bright dots, representative of single crystal.

It is shown that, by adding a crystallization promoter into the preceramic polymer, it is possible to get well-crystallized powders easily exfoliated to get 4- 3- 2- layers and even monolayers [103]. These sheets are used to get h-BN epitaxial graphene van der Waals heterostructures by deposing a drop of a solution of h-BN layers on ethanol on an epitaxial graphene, demonstrating the interest of these starting materials [105]. However, in any case, the BNNSs size remains critical to consider applications as graphene substrate or to modify the electronic properties. In that way, alternative ways have to be found in order to increase the domains' size and preserving the high crystallization level. 


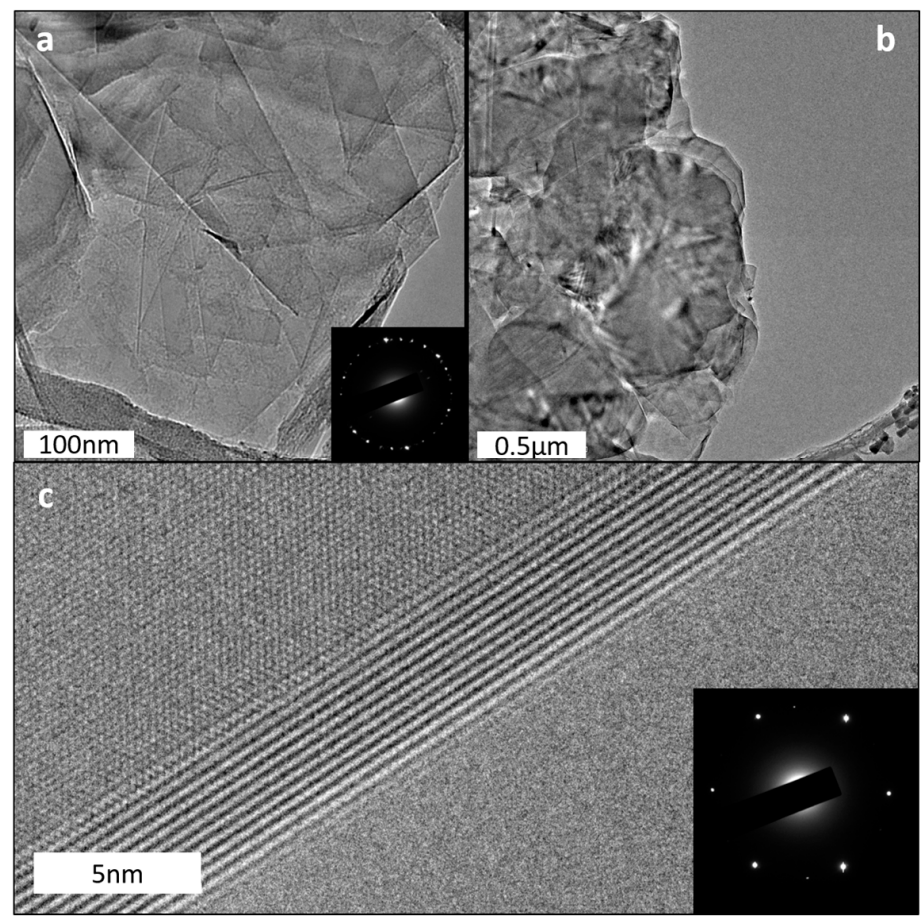

Figure 14. TEM images of the sample LiBN05: (a) Crystallized sheets stacked on each other; (b) Diffraction contrast between sheets evidencing the sample crystallization; (c) HRTEM image on a thin zone of a sheet (inset: corresponding SAED).

\section{Third Strategy: Combining PDCs with SPS}

Once we have been able to get pure and well-crystallized h-BN nanosheets using a crystallization promoter, the next step is to increase the lateral size of the obtained flakes. This step is of primary importance for the use of h-BN under different configurations: as an insulating substrate for graphene [57,58] or for creating new van der Waals heterostructures [61,106-108]. Our strategy is to combine the advantages of the PDCs route to those of the Spark Plasma Sintering (SPS) (Figure 15) process in order to synthesize important amount of pure, well-crystallized and large-scale $(>10 \mu \mathrm{m})$ h-BN flakes, which could be further easily exfoliated into BNNSs.

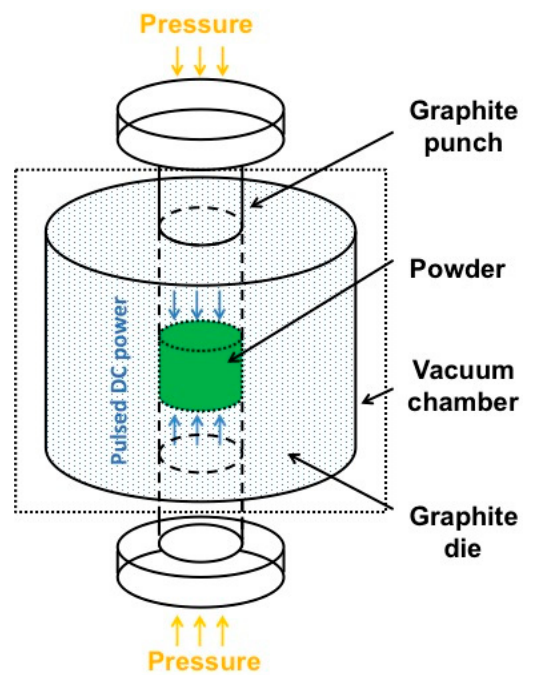

Figure 15. Scheme of the Spark Plasma Sintering. 
To perform the experiment, liquid PBN, mixed with $\mathrm{Li}_{3} \mathrm{~N}$ micro powder $(5 \mathrm{wt}$. \%) is preceramized at $650{ }^{\circ} \mathrm{C}$. The latter amorphous BN powder is then sintered by SPS in order to favor crystallization and increase crystals size. After sintering, we obtained a very dense white pellet of $2 \mathrm{~cm}$ in diameter.

\subsection{Characterization of the Bulk h-BN Pellet}

The white pellet (Figure 16) is first investigated by X-ray photoelectron spectroscopy before and after an Ar+ sputtering of the surface. Results obtained before abrasion of the surface gives an elemental B/N ratio of 0.97 , very close to the one of stoichiometric $\mathrm{BN}$ and consistent with reported XPS data for BN [109]. Carbon and oxygen contaminants are also observed attributed to extrinsic pollution as they disappear on the second analysis performed after $1 \mu \mathrm{m}$ abrasion ( $4 \mathrm{keV} \mathrm{Ar}+$ sputtering).

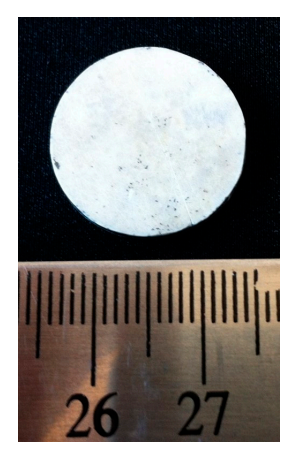

Figure 16. Image of the $2 \mathrm{~cm}$-diameter white pellet.

SEM performed on the same sample shows a homogeneous stacking of h-BN flakes (up to $30 \mu \mathrm{m}$ ) preferentially oriented perpendicularly to the pellet surface i.e. aligned in the compression direction and the external current (Figure 17a). A detailled flake is also presented on Figure $17 \mathrm{~b}$ to prove the large flake size.
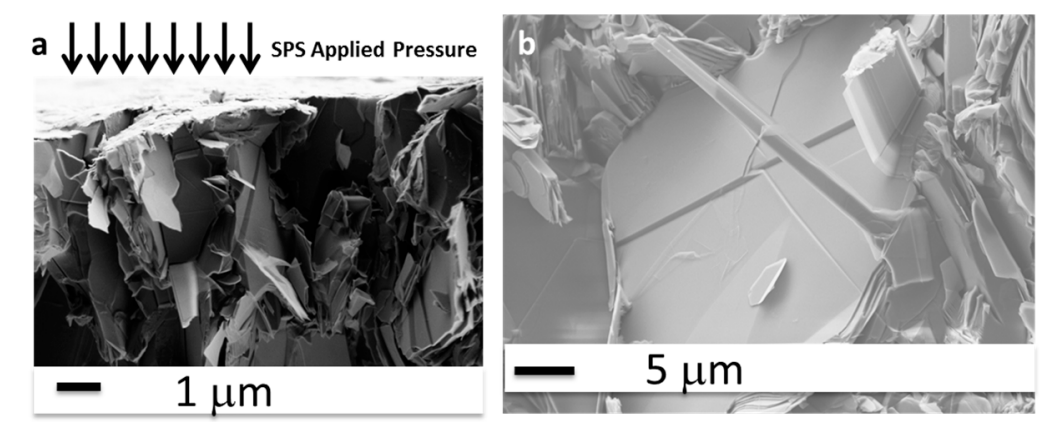

Figure 17. SEM performed on the bulk pellet: (a) Stacking of h-BN flakes; (b) Representative single flake.

The preferential orientation of the flakes is confirmed by X-ray diffraction recorded on both pellet surface and pellet cross-section (Figure 18). Even if both patterns exhibit thin, intense and well-separated peaks assigned to expected crystallographic planes from an h-BN crystal (JCPDS file 009-0012), the comparison of both diffractograms clearly shows a preferential orientation of the h-BN crystallites along the $a$-axis (characteristic of the covalent B-N bond), that is parallel to the applied load. 


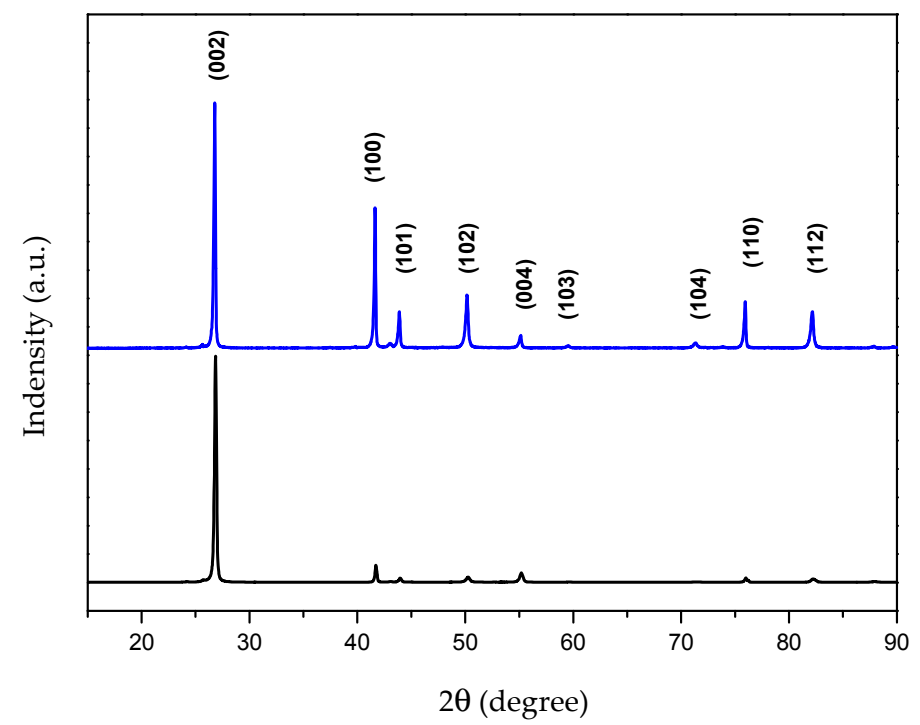

Figure 18. X-ray diffraction recorded on both pellet surface (blue) and pellet cross-section (black).

The good crystallinity of the sample deduced from the XRD patterns is also observed on the Raman spectrum (Figure 19). The well-defined symmetric single peak recorded at $1366 \mathrm{~cm}^{-1}$, which is characteristic of the $E_{2 g}$ vibration mode of h-BN crystal [33], presents a FWHM value of $7.7 \mathrm{~cm}^{-1}$ comparable to the best values reported for the h-BN single crystals obtained by HPHT $[77,78,89,110]$ and strongly improved compared to $17 \mathrm{~cm}^{-1}$ for PDCs BNNSs presented above. This last result evidences a very low defect density combined with a very large crystallite size.

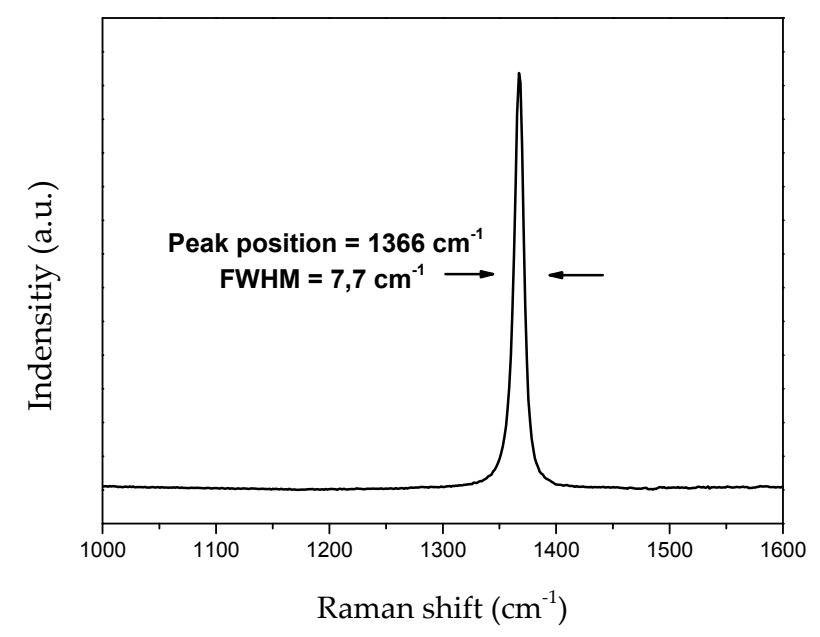

Figure 19. Raman spectrum recorded on a typical BNNS.

In summary, by coupling the PDCs method described above with SPS process, we can synthesize large micrometers-crystallized domains (up to $30 \mu \mathrm{m}$ ) of pure h-BN growing in the sintering load direction. From this sample, we have then prepared Boron Nitride Nano Sheets (BNNSs) by physical (tape) or chemical (in ethanol, ultrasonication: $1 \mathrm{~min}$ at $25 \mathrm{~W}$, Hielscher UP400S and centrifugation) exfoliation.

\subsection{Characterization of Single Crystal Flakes}

Flakes can be exfoliated by the tape method then deposited onto a Si substrate, covered by $80 \mathrm{~nm}$ $\mathrm{SiO}_{2}$ oxide layer. An optical examination reveals 10 to $300 \mathrm{~nm}$ (Figure 20b) thick pieces with side size 
up to $40 \mu \mathrm{m}$ (Figure 20c). Raman spectrum recorded on one flake (Figure 20a) displays the single peak of h-BN located at $1366 \mathrm{~cm}^{-1}$ with a $7.5 \mathrm{~cm}^{-1} \mathrm{FWHM}$, reflecting once more the excellent crystallinity of the flakes.
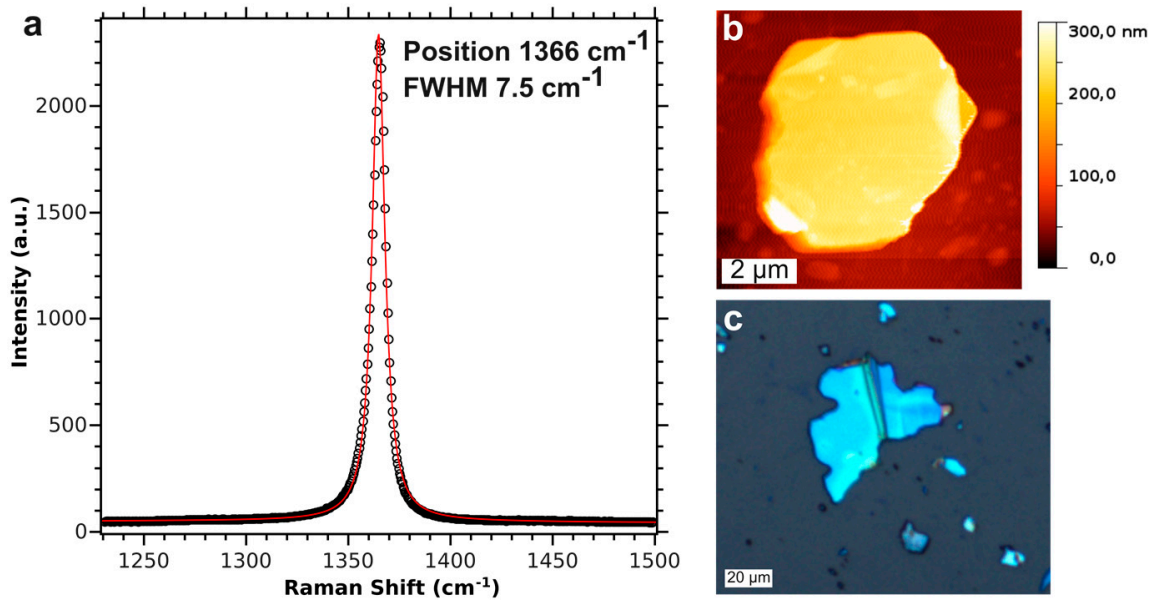

Figure 20. (a) Raman spectrum recorded on one h-BN single crystal flake; (b) AFM image of $300 \mathrm{~nm}$-thick flake; (c) Optical image of a side-size flake up to $50 \mu \mathrm{m}$.

TEM observations of 5-30 $\mu \mathrm{m}$ flakes confirmed the high crystalline quality of samples (Figure 21). Actually, diffraction contrast (dark areas correspond to crystallized zones of the flake in Bragg's position) (Figure 21a,b) visible on a reprensentative flake (Figure 21a) attests the crystallinity of the final ceramic. Figure 21c represents a TEM image of the edge of the flake showing the perfect staking of BNNSs composing the flake.

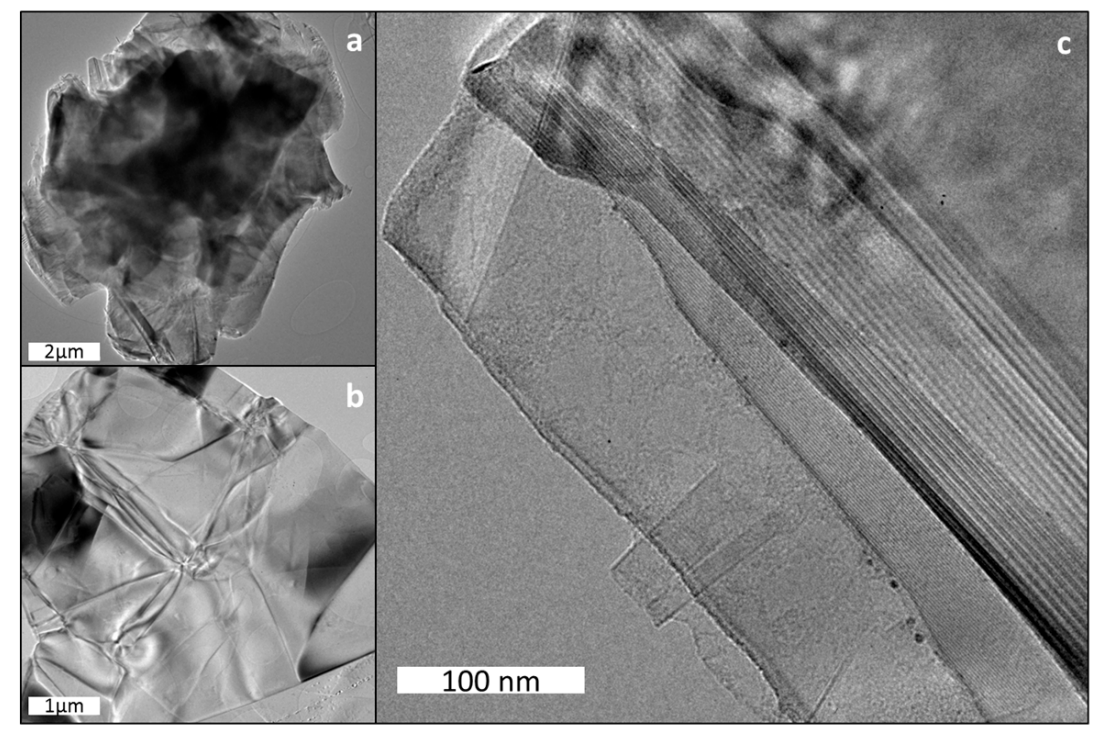

Figure 21. TEM observations performed on 5-30 $\mu \mathrm{m}$ flakes: (a) and (b) BF-TEM images showing diffraction contrast; (c) TEM image of the edge of the flake proving the staking of BNNSs composing the flake.

\subsection{Characterisation of the BNNS}

The size distribution of the crystals before chemical exfoliation, and of the BNNSs after chemical exfoliation, has been respectively studied from SEM and optical images [76]. After exfoliation, BNNSs thickness slows down to several nanometers and the BNNSs size (10 to $15 \mu \mathrm{m} v \mathrm{~s} .30 \mu \mathrm{m}$ for crystals) 
is lowered. The surface roughness of h-BN deposited onto $\mathrm{SiO}_{2}$ substrate has then been measured by AFM and the RMS (Root Mean Square) value has been determined to $0.7 \mathrm{~nm}$, similar to the one measured for standard silica. This means that our samples would be flat enough to be used as graphene substrates or to produce Van der Waals heterostructures. A droplet of the chemical solution was then simply deposited onto a 300 mesh holey carbon copper grid in order to perform TEM observations. Figure 22a proposes a typical TEM image obtained on 5-10 $\mu \mathrm{m}$ size BNNSs. Another image (Figure 22b) still performed on a typical sample shows how the BNNSs delaminate from each to other leading to a large amount of nanolayers. Finer observation by HRTEM allows to get image of a 4- layers BNNS, the thickness being determined counting the dark lines. SAED pattern (Figure 22c, inset), obtained from the high resolution image (Figure 22), shows six bright spots hexagonally distributed, demonstrating the achievement of well crystallised h-BN. This SAED pattern can be interpreted as the AA' atomic stacking along the c-direction.

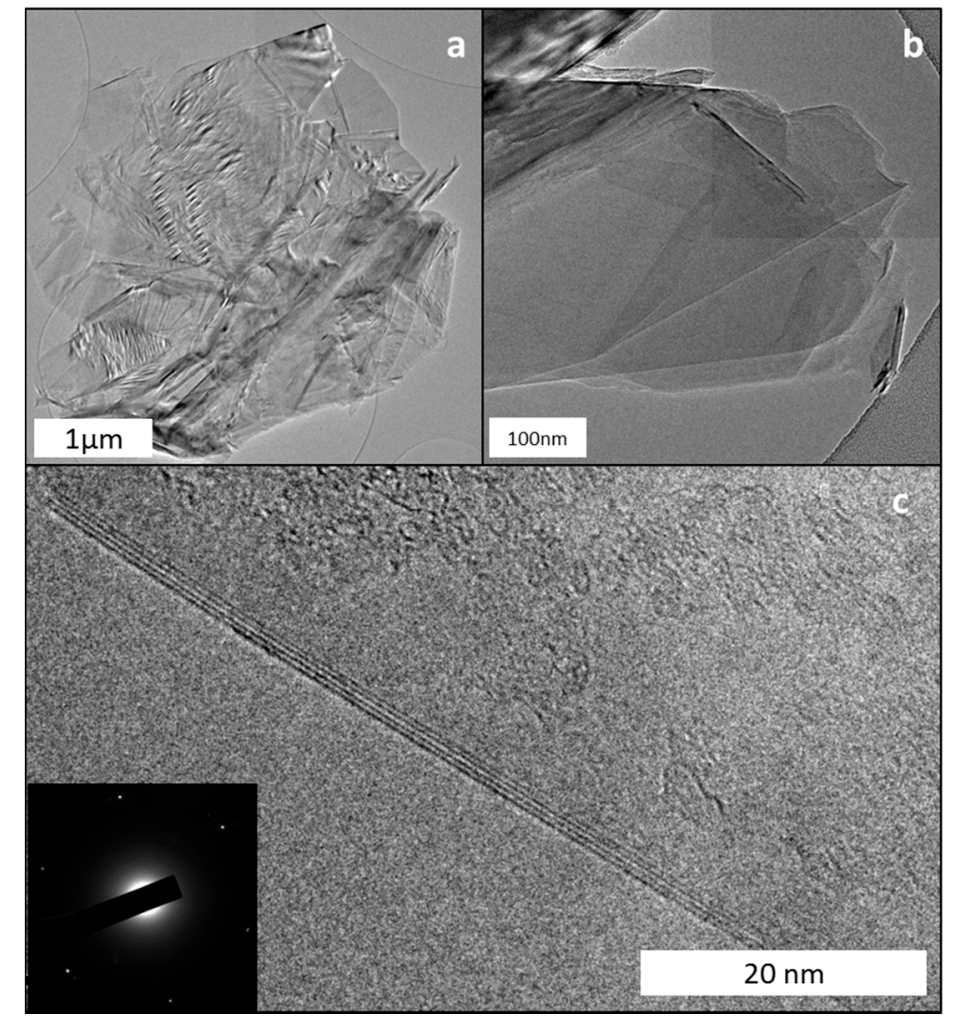

Figure 22. TEM observations performed on thin BNNSs: (a) Representive TEM image obtained on a 5-10 $\mu \mathrm{m}$ size BNNS; (b) TEM image showing BNNSs delamination; (c) HRTEM image obtained on a 4-layers BNNS (inset: corresponding SAED).

Finally, EELS spectra are recorded on thin BNNSs and show only boron and nitrogen K-edges without any trace of lithium, carbon or oxygen, corroborating previous XPS results on the excellent purity of samples.

To conclude, by combining PDCs route with SPS method, we associated the synthesis of high purity ceramic to the high crystallinity sintering. We obtained very pure and well crystallized large flakes (up to $30 \mu \mathrm{m}$ ) orientated along the compressed direction. By exfoliating these flakes, we can obtain a large amount of self-standing h-BN few-layers whose quality may open new perspectives for many applications as graphene substrate or to produce van der Waals heterostructures. 


\section{Materials and Methods}

\subsection{Borazine and PBN Syntheses}

Pure borazine $\left(\mathrm{B}_{3} \mathrm{~N}_{3} \mathrm{H}_{6}\right)$ is obtained from a reaction between ammonium sulfate $\left[\left(\mathrm{NH}_{4}\right)_{2} \mathrm{SO}_{4}\right.$, $99 \%$ purity, Aldrich] and sodium borohydride $\left(\mathrm{NaBH}_{4}, 98 \%\right.$ purity, Aldrich) in tetraglyme heated to $120{ }^{\circ} \mathrm{C}$ according to a procedure described elsewhere [111]. After purification by distillation, borazine is then heated at $50{ }^{\circ} \mathrm{C}$ inside a pressure-sealed system under argon for 5 days, generating a colorless polyborazilene (PBN). PBN is kept below $4{ }^{\circ} \mathrm{C}$ to exclude further polymer reticulation. Elemental analysis performed on the used PBN gives the general chemical formula $\left(\mathrm{B}_{3.0} \mathrm{~N}_{3.8} \mathrm{H}_{4.0}\right)_{\mathrm{n}}$. When necessary, lithium nitride $\left(\mathrm{Li}_{3} \mathrm{~N}\right.$, Aldrich) micro powders in different percentage (more often: $5 \mathrm{wt} . \%$ ) is added to PBN, and the mixture is kept with stirring in a Schlenk tube under argon for $10 \mathrm{~min}$. The mixture is then used as such or after a preceramisation process hold into an alumina crucible under $\mathrm{N}_{2}$, at $650{ }^{\circ} \mathrm{C}\left(1{ }^{\circ} \mathrm{C} / \mathrm{min}\right)$ and kept at this final temperature for $1 \mathrm{~h}$.

\subsection{Characteization Tools}

X-ray PhotoSpectrospy (XPS) data are recorded using a PHI Quantera SXM instrument (Physical Electronics, Chanhassen, MN, USA) equipped with a 180 hemispherical electron energy analyzer and a monochromatized $\mathrm{Al} \mathrm{K} \alpha(1486.6 \mathrm{eV})$ source operated at $15 \mathrm{kV}$ and $4 \mathrm{~mA}$. ThermoGravimetric Analyses (TGA) are performed with a TGA/SDTA 851 (Mettler Toledo, Colombus, OH, US), under $50 \mathrm{~mL} / \mathrm{min} \mathrm{N}_{2}$ from 25 to $1400{ }^{\circ} \mathrm{C}$ in an alumina crucible (at a rate of $20^{\circ} \mathrm{C} / \mathrm{min}$ ). The Raman scattering measurements are collected either with an XY Dilor triple spectrometer followed by a nitrogen-cooled CCD (charge-coupled device) multichannel detector or using a Horiba Jobin-Yvon ARAMIS spectrometer (Horiba, Kyoto, Japan) equipped with a 1800 lines/nm grating, using an excitation wavelength of $532 \mathrm{~nm}$ and a $\times 50$ objective (the main Raman band of the silica peak is located at $520.1 \mathrm{~cm}^{-1}$ ). X-ray Diffraction (XRD) analyses (Phillips PW 1830/40 (Phillips, Amsterdam, Netherlands)) with a $\mathrm{Cu}-K$ radiation source are carried out at room temperature. Transmission Electronic Microscopy (TEM) observation is performed using a JEOL 2100F (Jeol, Tokyo, Japan) and 2010F microscopes operating at 200 kV. Electron Energy Lost Spectroscopy (EELS) spectra are recorded using a JEOL JEM-ARM200F Cold FEG (Jeol, Tokyo, Japan), operating at 200 kV. Scanning Electron Microscopy (SEM) is performed with a SUPRA Zeiss (Supra Zeiss, Iena, Germany) at very low accelerating voltage (200 V).

\subsection{Specific Apparatus}

IR irradiation annealing. Two annealing processes are used in the context of this study. The first employs a halogen lamp with a gold reflector MR16 (OSRAM, XENOPHOT, Munich, Germany)) in a gloves box filled with argon. Voltage power was increased $\left(100^{\circ} \mathrm{C} / \mathrm{min}\right)$ until the final temperature is reached, and samples are then hold at this temperature for $90 \mathrm{~min}$. In the second process, samples are placed in a Rapid Thermal Annealing (RTA) cold wall chamber furnace (AS-One, ANNEALSYS Montpellier, France). Temperature is monitored via pyrometer placed under the sample's back face. Samples are rapidly heated to $900{ }^{\circ} \mathrm{C}$, then 6 or 9 irradiation flashes of $5 \mathrm{~s}$ with $100 \%$ lamp power (with a final temperature estimated around $1350{ }^{\circ} \mathrm{C}$ ) are delivered in one of two gas atmospheres (argon or nitrogen), allowing the sample to return to $900^{\circ} \mathrm{C}$ between flashes.

Spark Plasma Sintering. In a gloves box, the SPS graphite die covered with a papyex ${ }^{\circledR}$ is filled with the preceramic powder and then transferred into the SPS chamber (HP D 25, FCT System (FCT Systeme Gmbh, Rauenstein, Germany)) in-between the two punches and compressed at room temperature under uniaxial load until $90 \mathrm{MPa}$. SPS heating (10 ms pulses ON and $5 \mathrm{~ms}$ OFF) is then conducted up to $1800{ }^{\circ} \mathrm{C}$ keeping the normal load constant. During the $1 \mathrm{~h}$ dwell temperature the current is $770 \mathrm{~A}$ and the vacuum in the SPS chamber is 0.15 mbar. 


\section{Conclusions}

This review reports several strategies to synthesis highly crystallized hexagonal boron nitride using the Polymer Derived Ceramics (PDCs) route. This route, which is a great alternative in preparing specific ceramic shapes starting from a tailored polymeric precursor, is often associated with a drastic thermal annealing to get a well-crystallized material. Indeed, due to either equipment or substrate limitations, the implementation of a severe conventional thermal treatment is not often possible. In that context, our group develops the original strategies avoiding high temperature processes with the main goal to reach high performances micrometric h-BN coatings deposited on thermal sensitive substrate and self-standing boron nitride nanolayers. First, we have shown that using an annealing under infrared irradiation led to lower the onset crystallization temperature of about $300{ }^{\circ} \mathrm{C}$ compared to a conventional thermal treatments. Secondly, we presented a study on the effect of the additivation of pure polyborazilene with lithium nitride as crystallization promoter. In that case, it is proven that additivation of $5 \mathrm{wt}$. $\% \mathrm{Li}_{3} \mathrm{~N}$ allows preparing highly crystallized h-BN from $1200{ }^{\circ} \mathrm{C}$. Finally, the unique combination of the PDCs route with a relevant sintering process by Spark Plasma Sintering leads to an accessible source of single crystals of h-BN available for a further exfoliation. Using one or the other or combining the complementary approaches, may give rise to high performance devices suitable for aeronautic or electronic applications.

Acknowledgments: Authors gratefully acknowledge the ANR for its financial support through the project 14-CE08-0018 «GoBN», the CT $\mu$ (Centre Technologique des Microstructures) of the Université Lyon 1 and CLYM (Centre Lyonnais de Microscopie) for access to TEMs.

Author Contributions: All authors contributed to the experiments and discussions presented in this review.

Conflicts of Interest: The authors declare no conflict of interest.

\section{References}

1. Paine, R.T.; Narula, C.K. Synthetic routes to boron nitride. Chem. Rev. 1990, 90, 73-91. [CrossRef]

2. Han, W.-Q. Anisotropic Hexagonal Boron Nitride Nanomaterials: Synthesis and Applications. In Nanotechnologies for the Life Sciences; Wiley-VCH Verlag GmbH \& Co. KGaA: Weinheim, Germany, 2007.

3. Jiang, X.-F.; Weng, Q.; Wang, X.-B.; Li, X.; Zhang, J.; Golberg, D.; Bando, Y. Recent Progress on Fabrications and Applications of Boron Nitride Nanomaterials: A Review. J. Mater. Sci. Technol. 2015, 31, 589-598. [CrossRef]

4. Toury, B.; Miele, P. A new polyborazine-based route to boron nitride fibres. J. Mater. Chem. 2004, 14, 2609-2611. [CrossRef]

5. Toury, B.; Bernard, S.; Cornu, D.; Chassagneux, F.; Létoffé, J.-M.; Miele, P. High-performance boron nitride fibers obtained from asymmetric alkylaminoborazine. J. Mater. Chem. 2003, 13, 274-279. [CrossRef]

6. Toury, B.; Miele, P.; Cornu, D.; Vincent, H.; Bouix, J. Boron Nitride Fibers Prepared from Symmetric and Asymmetric Alkylaminoborazines. Adv. Funct. Mater. 2002, 12, 228-234. [CrossRef]

7. Miele, P.; Bernard, S.; Cornu, D.; Toury, B. Recent Developments in Polymer-Derived Ceramic Fibers (PDCFs): Preparation, Properties and Applications-A Review. Soft Mater. 2007, 4, 249-286. [CrossRef]

8. Bernard, S.; Ayadi, K.; Berthet, M.-P.; Chassagneux, F.; Cornu, D.; Letoffe, J.-M.; Miele, P. Evolution of structural features and mechanical properties during the conversion of poly[(methylamino)borazine] fibers into boron nitride fibers. J. Solid State Chem. 2004, 177, 1803-1810. [CrossRef]

9. Kalay, S.; Yilmaz, Z.; Sen, O.; Emanet, M.; Kazanc, E.; Çulha, M. Synthesis of boron nitride nanotubes and their applications. Beilstein J. Nanotechnol. 2015, 6, 84-102. [CrossRef] [PubMed]

10. Tiano, A.L.; Park, C.; Lee, J.W.; Luong, H.H.; Gibbons, L.J.; Chu, S.-H.; Applin, S.; Gnoffo, P.; Lowther, S.; Kim, H.J.; et al. Boron nitride nanotube: Synthesis and applications. Proc. SPIE 2014, 9060. [CrossRef]

11. Wang, J.; Lee, C.H.; Bando, Y.; Golberg, D.; Yap, Y.K. Multiwalled Boron Nitride Nanotubes: Growth, Properties, and Applications. In B-C-N Nanotubes and Related Nanostructures; Springer New York: New York, NY, USA, 2009; pp. 23-44. 
12. Stéphan, O.; Bando, Y.; Loiseau, A.; Willaime, F.; Shramchenko, N.; Tamiya, T.; Sato, T. Formation of small single-layer and nested BN cages under electron irradiation of nanotubes and bulk material. Appl. Phys. A 1998, 67, 107-111. [CrossRef]

13. Golberg, D.; Bando, Y.; Stéphan, O.; Kurashima, K. Octahedral boron nitride fullerenes formed by electron beam irradiation. Appl. Phys. Lett. 1998, 73, 2441-2443. [CrossRef]

14. Lin, Y.; Connell, J.W. Advances in 2D boron nitride nanostructures: Nanosheets, nanoribbons, nanomeshes, and hybrids with graphene. Nanoscale 2012, 4, 6908. [CrossRef] [PubMed]

15. Arenal, R.; Lopez-Bezanilla, A. Boron nitride materials: An overview from 0D to 3D (nano)structures. Wiley Interdiscip. Rev. Comput. Mol. Sci. 2015, 5, 299-309. [CrossRef]

16. Haubner, R.; Wilhelm, M.; Weissenbacher, R.; Lux, B. Boron Nitrides_Properties, Synthesis and Applications; Springer Berlin Heidelberg: Berlin, Germany; Heidelberg, Germany, 2002.

17. Clere, T.M. Method for Making High Thermal Diffusivity Boron Nitride Powders. Google Patents US 6764975 B1, 20 July 2004.

18. Lin, K.Y.; Raman, C.; Xiang, B.; Murugaiah, A. Composition Comprising Exfoliated Boron Nitride and Method for Forming Such Compositions. Google Patents US 20140077125 A1, 20 March 2014.

19. Chantrell, P.G.; Popper, P. Inorganic Polymers for Ceramics; Special Ceramics; Academic Press; Popper: New York, NY, USA, 1965; Volume 4.

20. Colombo, P.; Mera, G.; Riedel, R.; Sorarù, G.D. Polymer-Derived Ceramics: 40 Years of Research and Innovation in Advanced Ceramics: Polymer-Derived Ceramics. J. Am. Ceram. Soc. 2010, 93, 1805-1837. [CrossRef]

21. Bernard, S.; Salameh, C.; Miele, P. Boron nitride ceramics from molecular precursors: Synthesis, properties and applications. Dalton Trans. 2016, 45, 861-873. [CrossRef] [PubMed]

22. Rice, R. Ceramics from polymer pyrolysis, opportunities and needs-A materials perspective. Am. Ceram. Soc. Bull. 1983, 62, 889-892.

23. Walker, B.; Rice, R.; Becher, P.; Bender, B.; Coblenz, W. Preparation and properties of monolithic and composite ceramics produced by polymer pyrolysis. Am. Ceram. Soc. Bull. 1983, 62, 916-923.

24. Wynne, K.J.; Rice, R.W. Ceramics Via Polymer Pyrolysis dagger. Annu. Rev. Mater. Sci. 1984, 14, $297-334$. [CrossRef]

25. Bernard, S.; Miele, P. Polymer-Derived Boron Nitride: A Review on the Chemistry, Shaping and Ceramic Conversion of Borazine Derivatives. Materials 2014, 7, 7436-7459. [CrossRef]

26. Kusari, U.; Bao, Z.; Cai, Y.; Ahmad, G.; Sandhage, K.H.; Sneddon, L.G. Formation of nanostructured, nanocrystalline boron nitride microparticles with diatom-derived 3-D shapes. Chem. Commun. 2007, 1177-1179. [CrossRef] [PubMed]

27. Zhong, W.; Wang, S.; Li, J.; Bechelany, M.C.; Ghisleni, R.; Rossignol, F.; Balan, C.; Chartier, T.; Bernard, S.; Miele, P. Design of carbon fiber reinforced boron nitride matrix composites by vacuum-assisted polyborazylene transfer molding and pyrolysis. J. Eur. Ceram. Soc. 2013, 33, 2979-2992. [CrossRef]

28. Li, J.; Bernard, S.; Salles, V.; Gervais, C.; Miele, P. Preparation of Polyborazylene-Derived Bulk Boron Nitride with Tunable Properties by Warm-Pressing and Pressureless Pyrolysis. Chem. Mater. 2010, 22, $2010-2019$. [CrossRef]

29. Alauzun, J.G.; Ungureanu, S.; Brun, N.; Bernard, S.; Miele, P.; Backov, R.; Sanchez, C. Novel monolith-type boron nitride hierarchical foams obtained through integrative chemistry. J. Mater. Chem. 2011, 21, 14025-14030. [CrossRef]

30. Termoss, H.; Toury, B.; Brioude, A.; Dazord, J.; Le Brusq, J.; Miele, P. High purity boron nitride thin films prepared by the PDCs route. Surf. Coat. Technol. 2007, 201, 7822-7828. [CrossRef]

31. Yuan, S.; Toury, B.; Benayoun, S. Novel chemical process for preparing h-BN solid lubricant coatings on titanium-based substrates for high temperature tribological applications. Surf. Coat. Technol. 2015, 272, 366-372. [CrossRef]

32. Termoss, H.; Toury, B.; Pavan, S.; Brioude, A.; Bernard, S.; Cornu, D.; Valette, S.; Benayoun, S.; Miele, P. Preparation of boron nitride-based coatings on metallic substrates via infrared irradiation of dip-coated polyborazylene. J. Mater. Chem. 2009, 19, 2671-2674. [CrossRef]

33. Yuan, S.; Benayoun, S.; Brioude, A.; Dezellus, O.; Beaugiraud, B.; Toury, B. New potential for preparation of performing h-BN coatings via polymer pyrolysis in RTA furnace. J. Eur. Ceram. Soc. 2013, 33, 393-402. [CrossRef] 
34. Lattemann, M.; Sell, K.; Ye, J.; Persson, P.Å.O.; Ulrich, S. Stress reduction in nanocomposite coatings consisting of hexagonal and cubic boron nitride. Thin Films 2006, 200, 6459-6464. [CrossRef]

35. Mitu, B.; Bilkova, P.; Marotta, V.; Orlando, S.; Santagata, A. RF plasma reactive pulsed laser deposition of boron nitride thin films. Appl. Surf. Sci. 2005, 247, 123-127. [CrossRef]

36. Mroz, W.; Kosydar, R.; Jelinek, M.; Kocourek, T.; Major, B. Phase formation and microstructure of boron nitride thin layers deposited using Nd:YAG and KrF lasers. Thin Films 2006, 200, 6438-6443. [CrossRef]

37. Greber, T.; Brandenberger, L.; Corso, M.; Tamai, A.; Osterwalder, J. Single layer hexagonal boron nitride films on Ni(110). E-J. Surf. Sci. Nanotechnol. 2006, 4, 410-413. [CrossRef]

38. Ćavar, E.; Westerström, R.; Mikkelsen, A.; Lundgren, E.; Vinogradov, A.S.; Ng, M.L.; Preobrajenski, A.B.; Zakharov, A.A.; Mårtensson, N. A single h-BN layer on Pt(1 1 1). Surf. Sci. 2008, 602, 1722-1726. [CrossRef]

39. Le Gallet, S.; Chollon, G.; Rebillat, F.; Guette, A.; Bourrat, X.; Naslain, R.; Couzi, M.; Bruneel, J. Microstructural and microtextural investigations of boron nitride deposited from $\mathrm{BCl} 3-\mathrm{NH} 3-\mathrm{H} 2$ gas mixtures. J. Eur. Ceram. Soc. 2004, 24, 33-44. [CrossRef]

40. Deb, B.; Bhattacharjee, B.; Ganguli, A.; Chaudhuri, S.; Pal, A.K. Boron nitride films synthesized by RF plasma CVD of borane-ammonia and nitrogen. Mater. Chem. Phys. 2002, 76, 130-136. [CrossRef]

41. Dekempeneer, E.H.A.; Kuypers, S.; Vercammen, K.; Meneve, J.; Smeets, J.; Gibson, P.N.; Gissler, W. Scratch-resistant transparent boron nitride films. Surf. Coat. Technol. 1998, 100-101, 45-48. [CrossRef]

42. Soltani, A.; Thévenin, P.; Bath, A. Optical properties of boron nitride thin films deposited by microwave PECVD. Mater. Sci. Eng. B 2001, 82, 170-172. [CrossRef]

43. Yuan, S. Elaboration de Revêtements de Nitrure (h-BN et SI3N4) par Pyrolyse de Polymere Précéramique: Caractérisations Chimiques, Structurales, Mécaniques et Tribologiques. Ph.D. Thesis, Ecole Centrale de Lyon, Ecully, France, 2013.

44. Middleman, S. The role of gas-phase reactions in boron nitride growth by chemical vapor deposition. Mater. Sci. Eng. A 1993, 163, 135-140. [CrossRef]

45. Kho, J.-G.; Moon, K.-T.; Nouet, G.; Ruterana, P.; Kim, D.-P. Boron-rich boron nitride (BN) films prepared by a single spin-coating process of a polymeric precursor. Thin Solid Films 2001, 389, 78-83. [CrossRef]

46. Design, Processing, and Properties of Ceramic Materials from Preceramic Precursors. In Materials Science and Technologies; Bernard, S., Ed.; Nova Science Publishers: New York, NY, USA, 2012.

47. Beck, J.S.; Albani, C.R.; McGhie, A.R.; Rothman, J.B.; Sneddon, L.G. Dibromoborane-dimethyl sulfide: A simple molecular precursor for the formation of bulk powders and fiber coatings of boron nitride. Chem. Mater. 1989, 1, 433-438. [CrossRef]

48. Bonnetot, B.; Guilhon, F.; Viala, J.C.; Mongeot, H. Boron Nitride Matrixes and Coatings Obtained from Tris(methylamino)borane. Application to the Protection of Graphite against Oxidation. Chem. Mater. 1995, 7, 299-303. [CrossRef]

49. Thévenot, F.; Doche, C.; Mongeot, H.; Guilhon, F.; Miele, P.; Cornu, D.; Bonnetot, B. Boron Nitride Obtained from Molecular Precursors: Aminoboranes Used as a BN Source for Coatings, Matrix, and Si3N4-BN Composite Ceramic Preparation. J. Solid State Chem. 1997, 133, 164-168. [CrossRef]

50. Cornu, D.; Miele, P.; Toury, B.; Bonnetot, B.; Mongeot, H.; Bouix, J. Boron nitride matrices and coatings from boryl borazine molecular precursors. J. Mater. Chem. 1999, 9, 2605-2610. [CrossRef]

51. Borek, T.T.; Qiu, X.; Rayfuse, L.M.; Datye, A.K.; Paine, R.T.; Allard, L.F. Boron Nitride Coatings on Oxide Substrates: Role of Surface Modifications. J. Am. Ceram. Soc. 1991, 74, 2587-2591. [CrossRef]

52. Paciorek, K.J.L.; Masuda, S.R.; Kratzer, R.H.; Schmidt, W.R. Processible precursor for boron nitride coatings and matrixes. Chem. Mater. 1991, 3, 88-91. [CrossRef]

53. Kim, D.P.; Economy, J. Fabrication of oxidation-resistant carbon fiber/boron nitride matrix composites. Chem. Mater. 1993, 5, 1216-1220. [CrossRef]

54. Cavallo, F.; Rojas Delgado, R.; Kelly, M.M.; Sánchez Pérez, J.R.; Schroeder, D.P.; Xing, H.G.; Eriksson, M.A.; Lagally, M.G. Exceptional Charge Transport Properties of Graphene on Germanium. ACS Nano 2014, 8, 10237-10245. [CrossRef] [PubMed]

55. Dean, C.R.; Young, A.F.; Meric, I.; Lee, C.; Wang, L.; Sorgenfrei, S.; Watanabe, K.; Taniguchi, T.; Kim, P.; Shepard, K.L.; Hone, J. Boron nitride substrates for high-quality graphene electronics. Nat. Nanotechnol. 2010, 5, 722-726. [CrossRef] [PubMed]

56. Gannett, W.; Regan, W.; Watanabe, K.; Taniguchi, T.; Crommie, M.F.; Zettl, A. Boron nitride substrates for high mobility chemical vapor deposited graphene. Appl. Phys. Lett. 2011, 98, 242105. [CrossRef] 
57. Lee, G.-H.; Yu, Y.-J.; Lee, C.; Dean, C.; Shepard, K.L.; Kim, P.; Hone, J. Electron tunneling through atomically flat and ultrathin hexagonal boron nitride. Appl. Phys. Lett. 2011, 99, 243114. [CrossRef]

58. Golberg, D.; Bando, Y.; Huang, Y.; Terao, T.; Mitome, M.; Tang, C.; Zhi, C. Boron Nitride Nanotubes and Nanosheets. ACS Nano 2010, 4, 2979-2993. [CrossRef] [PubMed]

59. Decker, R.; Wang, Y.; Brar, V.W.; Regan, W.; Tsai, H.-Z.; Wu, Q.; Gannett, W.; Zettl, A.; Crommie, M.F. Local Electronic Properties of Graphene on a BN Substrate via Scanning Tunneling Microscopy. Nano Lett. 2011, 11, 2291-2295. [CrossRef] [PubMed]

60. Xue, J.; Sanchez-Yamagishi, J.; Bulmash, D.; Jacquod, P.; Deshpande, A.; Watanabe, K.; Taniguchi, T.; Jarillo-Herrero, P.; LeRoy, B.J. Scanning tunnelling microscopy and spectroscopy of ultra-flat graphene on hexagonal boron nitride. Nat. Mater. 2011, 10, 282-285. [CrossRef] [PubMed]

61. Song, L.; Ci, L.; Lu, H.; Sorokin, P.B.; Jin, C.; Ni, J.; Kvashnin, A.G.; Kvashnin, D.G.; Lou, J.; Yakobson, B.I.; et al. Large scale growth and characterization of atomic hexagonal boron nitride layers. Nano Lett. 2010, 10, 3209-3215. [CrossRef] [PubMed]

62. Shi, Y.; Hamsen, C.; Jia, X.; Kim, K.K.; Reina, A.; Hofmann, M.; Hsu, A.L.; Zhang, K.; Li, H.; Juang, Z.-Y.; et al. Synthesis of Few-Layer Hexagonal Boron Nitride Thin Film by Chemical Vapor Deposition. Nano Lett. 2010, 10, 4134-4139. [CrossRef] [PubMed]

63. Zhang, C.; Fu, L.; Zhao, S.; Zhou, Y.; Peng, H.; Liu, Z. Controllable Co-segregation Synthesis of Wafer-Scale Hexagonal Boron Nitride Thin Films. Adv. Mater. 2014, 26, 1776-1781. [CrossRef] [PubMed]

64. Gao, Y.; Ren, W.; Ma, T.; Liu, Z.; Zhang, Y.; Liu, W.-B.; Ma, L.-P.; Ma, X.; Cheng, H.-M. Repeated and Controlled Growth of Monolayer, Bilayer and Few-Layer Hexagonal Boron Nitride on Pt Foils. ACS Nano 2013, 7, 5199-5206. [CrossRef] [PubMed]

65. Lu, G.; Wu, T.; Yuan, Q.; Wang, H.; Wang, H.; Ding, F.; Xie, X.; Jiang, M. Synthesis of large single-crystal hexagonal boron nitride grains on $\mathrm{Cu}-\mathrm{Ni}$ alloy. Nat. Commun. 2015, 6. [CrossRef] [PubMed]

66. Caneva, S.; Weatherup, R.S.; Bayer, B.C.; Brennan, B.; Spencer, S.J.; Mingard, K.; Cabrero-Vilatela, A.; Baehtz, C.; Pollard, A.J.; Hofmann, S. Nucleation Control for Large, Single Crystalline Domains of Monolayer Hexagonal Boron Nitride via Si-Doped Fe Catalysts. Nano Lett. 2015, 15, 1867-1875. [CrossRef] [PubMed]

67. Park, J.-H.; Park, J.C.; Yun, S.J.; Kim, H.; Luong, D.H.; Kim, S.M.; Choi, S.H.; Yang, W.; Kong, J.; Kim, K.K.; et al. Large-Area Monolayer Hexagonal Boron Nitride on Pt Foil. ACS Nano 2014, 8, 8520-8528. [CrossRef] [PubMed]

68. Camilli, L.; Sutter, E.; Sutter, P. Growth of two-dimensional materials on non-catalytic substrates: H-BN/Au(111). 2D Mater. 2014, 1, 025003. [CrossRef]

69. Corso, M.; Auwärter, W.; Muntwiler, M.; Tamai, A.; Greber, T.; Osterwalder, J. Boron Nitride Nanomesh. Science 2004, 303, 217-220. [CrossRef] [PubMed]

70. Simonson, R.J.; Paffett, M.T.; Jones, M.E.; Koel, B.E. A vibrational study of borazine adsorbed on $\mathrm{Pt}(111)$ and Au(111) surfaces. Surf. Sci. 1991, 254, 29-44. [CrossRef]

71. Preobrajenski, A.B.; Nesterov, M.A.; Ng, M.L.; Vinogradov, A.S.; Mårtensson, N. Monolayer h-BN on lattice-mismatched metal surfaces: On the formation of the nanomesh. Chem. Phys. Lett. 2007, 446, 119-123. [CrossRef]

72. Sutter, P.; Lahiri, J.; Albrecht, P.; Sutter, E. Chemical Vapor Deposition and Etching of High-Quality Monolayer Hexagonal Boron Nitride Films. ACS Nano 2011, 5, 7303-7309. [CrossRef] [PubMed]

73. Kim, K.K.; Hsu, A.; Jia, X.; Kim, S.M.; Shi, Y.; Hofmann, M.; Nezich, D.; Rodriguez-Nieva, J.F.; Dresselhaus, M.; Palacios, T.; et al. Synthesis of Monolayer Hexagonal Boron Nitride on Cu Foil Using Chemical Vapor Deposition. Nano Lett. 2012, 12, 161-166. [CrossRef] [PubMed]

74. Tay, R.Y.; Griep, M.H.; Mallick, G.; Tsang, S.H.; Singh, R.S.; Tumlin, T.; Teo, E.H. T.; Karna, S.P. Growth of Large Single-Crystalline Two-Dimensional Boron Nitride Hexagons on Electropolished Copper. Nano Lett. 2014, 14, 839-846. [CrossRef] [PubMed]

75. Wang, L.; Wu, B.; Chen, J.; Liu, H.; Hu, P.; Liu, Y. Monolayer Hexagonal Boron Nitride Films with Large Domain Size and Clean Interface for Enhancing the Mobility of Graphene-Based Field-Effect Transistors. Adv. Mater. 2014, 26, 1559-1564. [CrossRef] [PubMed]

76. Yuan, S.; Linas, S.; Journet, C.; Steyer, P.; Garnier, V.; Bonnefont, G.; Brioude, A.; Toury, B. Pure \& crystallized 2D Boron Nitride sheets synthesized via a novel process coupling both PDCs and SPS methods. Sci. Rep. 2016, 6, 20388. [PubMed] 
77. Watanabe, K.; Taniguchi, T.; Kanda, H. Direct-bandgap properties and evidence for ultraviolet lasing of hexagonal boron nitride single crystal. Nat. Mater. 2004, 3, 404-409. [CrossRef] [PubMed]

78. Kubota, Y.; Watanabe, K.; Tsuda, O.; Taniguchi, T. Deep Ultraviolet Light-Emitting Hexagonal Boron Nitride Synthesized at Atmospheric Pressure. Science 2007, 317, 932-934. [CrossRef] [PubMed]

79. Termoss, H. Préparation de Revêtements de Nitrure de Bore $(\mathrm{BN})$ par voie Polymère Précéramique: Etude Des Paramètres d'élaboration: Caractérisations Physico-Chimiques. Ph.D. Thesis, Université Claude Bernard-Lyon I, Villeurbanne, France, 2009.

80. Kho, J.-G.; Moon, K.-T.; Kim, J.-H.; Kim, D.-P. Properties of Boron Nitride (BxNy) Films Produced by the Spin-Coating Process of Polyborazine. J. Am. Ceram. Soc. 2000, 83, 2681-2683. [CrossRef]

81. Chan, V.Z.-H.; Rothman, J.B.; Palladino, P.; Sneddon, L.G.; Composto, R.J. Characterization of boron nitride thin films prepared from a polymer precursor. J. Mater. Res. 1996, 11, 373-380. [CrossRef]

82. Vilcarromero, J.; Carreño, M.N.; Pereyra, I. Mechanical properties of boron nitride thin films obtained by RF-PECVD at low temperatures. Thin Solid Films 2000, 373, 273-276. [CrossRef]

83. Nemanich, R.J.; Solin, S.A.; Martin, R.M. Light scattering study of boron nitride microcrystals. Phys. Rev. $B$ 1981, 23, 6348-6356. [CrossRef]

84. Mera, G. Polymer Derived-Ceramic MicroElectroMechanical Systems (PDC-MEMS). In Design, Processing and Properties of Ceramic Materials from Preceramic Precursors. Materials Science and Technologies; Bernard, S., Ed.; Nova Science Publisher: New York, NY, USA, 2011.

85. Gervais, C.; Maquet, J.; Babonneau, F.; Duriez, C.; Framery, E.; Vaultier, M.; Florian, P.; Massiot, D. Chemically Derived BN Ceramics: Extensive 11B and 15N Solid-State NMR Study of a Preceramic Polyborazilene. Chem. Mater. 2001, 13, 1700-1707. [CrossRef]

86. Fazen, P.J.; Beck, J.S.; Lynch, A.T.; Remsen, E.E.; Sneddon, L.G. Thermally induced borazine dehydropolymerization reactions. Synthesis and ceramic conversion reactions of a new high-yield polymeric precursor to boron nitride. Chem. Mater. 1990, 2, 96-97. [CrossRef]

87. Sneddon, L.G.; Mirabelli, M.G.L.; Lynch, A.T.; Fazen, P.J.; Su, K.; Beck, J.S. Polymeric precursors to boron based ceramics. Pure Appl. Chem. 2009, 63, 407-410. [CrossRef]

88. Fazen, P.J.; Remsen, E.E.; Beck, J.S.; Carroll, P.J.; McGhie, A.R.; Sneddon, L.G. Synthesis, Properties, and Ceramic Conversion Reactions of Polyborazylene. A High-Yield Polymeric Precursor to Boron Nitride. Chem. Mater. 1995, 7, 1942-1956. [CrossRef]

89. Watanabe, K.; Taniguchi, T.; Kanda, H. Ultraviolet luminescence spectra of boron nitride single crystals grown under high pressure and high temperature. Phys. Status Solidi A 2004, 201, 2561-2565. [CrossRef]

90. Solozhenko, V.L.; Turkevich, V.Z. Kinetics of cBN crystallization in the Li3N-BN system at 6.6 GPa. Diam. Relat. Mater. 1998, 7, 43-46. [CrossRef]

91. Shipilo, V.B.; Ignatenko, O.V.; Shempel, N.A.; Azarko, I.I.; Lebedev, S.A. Crystallization of cubic boron nitride in the system Li3N-BN (4-10 wt \% Li3N). Inorg. Mater. 2011, 44, 258-262. [CrossRef]

92. Guo, X.-F.; Xu, B.; Zhang, W.; Lv, M.-Z.; Yang, H.-M.; Fan, X.-H. Thermodynamic Analysis about Nucleation and Growth of Cubic Boron Nitride Crystals in the hBN-Li3N System under High Pressure and High Temperature. Entropy 2015, 17, 755-762. [CrossRef]

93. Von der Gönna, J.; Meurer, H.J.; Nover, G.; Peun, T.; Schönbohm, D.; Will, G. In-situ investigations of the reversible $\mathrm{hBN}-\mathrm{cBN}-\mathrm{hBN}$-transformation in the Li3N-BN catalyst system using synchrotron radiation. Mater. Lett. 1998, 33, 321-326. [CrossRef]

94. Du, Y.; Su, Z.; Yang, D.; Yang, X.; Ji, X.; Gong, X.; Zhang, T. Synthesis of black cBN single crystal in hBN-Li3N-B system. Mater. Lett. 2007, 61, 3409-3412. [CrossRef]

95. Sheng Yuan, B.T. Low-Temperature Synthesis of Highly Crystallized Hexagonal Boron Nitride Sheets with Li3N as Additive Agent. Eur. J. Inorg. Chem. 2014, 2014. [CrossRef]

96. Solozhenko, V.L.; Turkevich, V.Z. High pressure phase equilibria in the Li3N-BN system: In situ studies. Mater. Lett. 1997, 32, 179-184. [CrossRef]

97. Yamane, H.; Kikkawa, S.; Koizumi, M. High- and low-temperature phases of lithium boron nitride, Li3BN2: Preparation, phase relation, crystal structure, and ionic conductivity. J. Solid State Chem. 1987, 71, 1-11. [CrossRef]

98. Jacobson, N.; Farmer, S.; Moore, A.; Sayir, H. High-Temperature Oxidation of Boron Nitride: I, Monolithic Boron Nitride. J. Am. Ceram. Soc. 1999, 82, 393-398. [CrossRef] 
99. Vincent, H.; Chassagneux, F.; Vincent, C.; Bonnetot, B.; Berthet, M.; Vuillermoz, A.; Bouix, J. Microtexture and structure of boron nitride fibres by transmission electron microscopy, X-ray diffraction, photoelectron spectroscopy and Raman scattering. Mater. Sci. Eng. A 2003, 340, 181-192. [CrossRef]

100. Bezrukov, G.; Butuzov, V.; Nikitina, T.; Feldgun, L.; Filonenk, N.E.; Khatelishvili, G.V. On crystallization of cubic boron nitride and of synthetic diamond. Dokl. Akad. NAUK SSSR 1968, 179, 1326.

101. Li, S.; Guo, X.; Xu, B.; Wang, H. Fracture morphology and XRD layered characterization of cBN cake. J. Synth. Cryst. 2012, 41, 15-19.

102. Xu, B.; Lv, M.-Z.; Yang, H.-M.; Wen, Z.-X. Thermodynamic Analysis of the V-Shaped Area of High Pressure and High Temperature in Cubic Boron Nitride Synthesis with Li3N as a Catalyst. Entropy 2014, 16, 912-920. [CrossRef]

103. Yuan, S.; Toury, B.; Journet, C.; Brioude, A. Synthesis of hexagonal boron nitride graphene-like few layers. Nanoscale 2014, 6, 7838-7841. [CrossRef] [PubMed]

104. Xu, L.Q.; Zhan, J.H.; Hu, J.Q.; Bando, Y.; Yuan, X.L.; Sekiguchi, T.; Mitome, M.; Golberg, D. High-Yield Synthesis of Rhombohedral Boron Nitride Triangular Nanoplates. Adv. Mater. 2007, 19, 2141-2144. [CrossRef]

105. Sediri, H.; Pierucci, D.; Hajlaoui, M.; Henck, H.; Patriarche, G.; Dappe, Y.J.; Yuan, S.; Toury, B.; Belkhou, R.; Silly, M.G.; et al. Atomically Sharp Interface in an h-BN-epitaxial graphene van der Waals Heterostructure. Sci. Rep. 2015, 5, 16465. [CrossRef] [PubMed]

106. Britnell, L.; Gorbachev, R.; Jalil, R.; Belle, B.; Schedin, F.; Mishchenko, A.; Georgiou, T.; Katsnelson, M.I.; Eaves, L.; Morozov, S.V.; et al. Field-effect tunneling transistor based on vertical graphene heterostructures. Science 2012, 335, 947-950. [CrossRef] [PubMed]

107. Mehr, W.; Dabrowski, J.C.; Scheytt, G.; Lippert, Y.H.; Xie, M.C.; Lemme, M.; Ostling, G. Lupina Vertical Graphene Base Transistor. IEEE Elect. Device Lett. 2012, 33, 691-693. [CrossRef]

108. Liu, Z.; Ma, L.; Shi, G.; Zhou, W.; Gong, Y.; Lei, S.; Yang, X.; Zhang, J.; Yu, J.; Hackenberg, K.P.; et al. In-plane heterostructures of graphene and hexagonal boron nitride with controlled domain sizes. Nat. Nanotechnol. 2013, 8, 119-124. [CrossRef] [PubMed]

109. Moulder, J.; Stickle, W.; Sobol, P.; Bomben, K. Handbook of X-ray Photoelectron Spectroscopy; Perkin-Elmer: Eden Prairie, MN, USA, 1992.

110. Clubine, B. Synthesis and Characterization of Bulk Single Crystal Hexagonal Boron Nitride from Metal Solvents; Kansas State University: Manhattan, KS, USA, 2012.

111. Wideman, T.; Sneddon, L.G. Convenient procedures for the laboratory preparation of borazine. Inorg. Chem. 1995, 34, 1002-1003. [CrossRef] 